\title{
Measured dynamic properties of web-core sandwich panel FRP composite footbridges and their relation to pedestrian comfort analysis
}

\author{
Jordi UYTTERSPROT1,a and Wouter DE CORTE2,b \\ ${ }^{1}$ PhD fellow strategic basic research at FWO - Flanders, Host institution Department of Structural \\ Engineering and Building Materials, Faculty of Engineering and Architecture, Ghent University, Valentin \\ Vaerwyckweg 1, 9000 Ghent, Belgium \\ ${ }^{2}$ Associate professor, Department of Structural Engineering and Building Materials, Faculty of Engineering \\ and Architecture, Ghent University, Valentin Vaerwyckweg 1, 9000 Ghent, Belgium \\ aJordi.Uyttersprot@UGent.be, ${ }^{b}$ Wouter.DeCorte@UGent.be
}

* Corresponding author

Wouter De Corte

Laboratory Magnel-Vandepitte for Structural Engineering and Building Materials

Department of Structural Engineering and Building Materials

Faculty of Engineering and Architecture

Ghent University

Valentin Vaerwyckweg 1, 9000 Ghent, Belgium

Phone: $+32.479 / 31.81 .85$

email: Wouter.DeCorte@UGent.be 


\begin{abstract}
This paper reports experimental data for the dynamic properties (i.e. first fundamental flexural frequency, damping ratio, comfort class) of ten web-core sandwich panel FRP composite footbridges in Belgium, which contributes to the assessment of relevant input parameters for design and assessment of this promising bridge type, quickly gaining popularity in recent years. The data is gathered based on smartphone accelerometers, enabling easy, quick, affordable, and abundant measurements, while at the same time yielding reliable experimental values. Given the relatively short spans, the heel and excitation test methods are used, rather than the ambient vibration method. The tests indicate damping ratios of one to three percent, which are strongly dependent on the number of people on the bridge during the measurement. Additionally, comfort analysis tests with up to 58 people $\left(0.5 \mathrm{P} / \mathrm{m}^{2}\right)$ were conducted on five out of the ten bridges. The results indicate that the current design guidelines for pedestrian comfort analysis are overconservative and do not reflect the effect of pedestrian-induced damping, which is especially apparent for this bridge type given its very low modal mass and relatively low damping ratio.
\end{abstract}

Keywords: FRP, Composite, Dynamic properties, Vibrations, Bridge building

\title{
1 Introduction
}

Human-induced vibrations on footbridges have gained a lot of attention in recent years, since the community demands for more aesthetically pleasing and slender bridges [1-3]. Moreover, improvements in materials, design methods, building techniques and the involvement of architects led to longer and more slender bridges. These have made footbridges more susceptible to human-induced vibrations [4-7], causing discomfort to pedestrians and compromising the utility of the structure [8,9], even though the bridge is structurally sound and safe to cross. Design codes address this dynamic problem by providing limits for natural frequency and simplistic provisions to keep the footbridge experience pleasant.

Due to the successful application of fibre-reinforced polymer (FRP) composite shapes and structures in the aviation, offshore, marine and wind turbine sectors, these materials are increasingly used in load-bearing civil engineering structures [10-13]. In bridge construction, mainly the good mechanical properties such as the high strength and stiffness-to-weight ratio compared to other traditional construction materials play an important role in the decisionmaking process of an FRP structure. In addition, the low maintenance costs and the speed and ease of installation are important points for the application of these materials in short and medium-length pedestrian and low to medium traffic bridges [14-16]. For slender, lightweight bridges such as glass fibre-reinforced polymer (GFRP) bridges, the dynamic problem can be onerous and require a refined analysis to demonstrate that the desired comfort level can be satisfied [17].

A web-core sandwich panel GFRP bridge consists of a vacuum-infused ribbed sandwich panel that acts as a deck structure, as well as the main load carrying structure [18-22]. In its basic simply supported configuration, spans of $20 \mathrm{~m}$ are realistic although in other configurations, larger spans are achieved through e.g. clamping of the abutments or intermediate support points [23,24]. For this type of bridge, due to the low self-weight compared to concrete and limited stiffness compared to steel, vertical deformation and human-induced vertical vibrations are the typical design criteria rather than ultimate strength [25-27]. It is therefore important to accurately assess the vibrational response of these ribbed sandwich type GFRP footbridges.

Furthermore, due to the low weight of the GFRP web-core footbridges, the non-structural mass of pedestrians on the bridge deck will play an important role in the overall vibration behaviour of the footbridge. Human-structure interaction [28-32] is a well-known phenomenon in which the 
dynamics of the two subsystems interact and they start to influence each other. Due to this interaction, certain dynamic properties, i.e. the first natural frequency and the structural damping ratio of the structure, can be modified to a significant extent [33-36]. However, current design guidelines do not take into account this human-structure interaction [37-40], which will lead to an under- or overestimation of the actual dynamic properties of the structure.

The vibration behaviour of footbridges under a pedestrian load is an important serviceability limit check. An inaccurate estimation of the vibration response in the bridge design can result in excessive vibrations during use. On the other hand, very conservative vibration response estimation models will lead to oversizing and consequently a very high weight, emission impact, and production cost. However, only a few studies have been performed to accurately depict the vibrational behaviour of GFRP structures such as footbridges [1,25,27,41,42].

In this paper, on the basis of various tests on ten GFRP web-core footbridges in Flanders, a first insight will be given with regard to the first natural frequency, the damping ratio and the associated comfort of these bridges. The contribution of this paper mainly consists of:

- Collecting accurate vibration data in a simple, cheap and reliable way using smartphone accelerometers;

- Defining simple test methods to determine the vibration properties of the bridge such as the natural frequency and the damping ratio;

- An initial estimate of the minimum, maximum and average value of the natural frequency and damping ratio of the tested GFRP web-core footbridges;

- Assessment of the standards and guidelines in the context of the comfort requirements and the associated limit for the natural frequency above which no resonance of the bridge is expected under a pedestrian flow;

- A comparison between an analytical calculation model based on one of the tested bridges and the currently available guidelines, and the actual measured vibration properties.

In section 2 of this paper, a brief description and the geometrical properties of the studied GFRP web-core footbridges in the Flanders region of Belgium $[23,43]$ will be given. Section 3 first describes the measurement method via the VibSensor [44] smartphone application, followed by a description of the heel and excitation tests and the results related to the first natural flexural frequency and the bridge structural damping ratio. The comfort analysis of five GFRP web-core footbridges for two loading situations (i.e. walking and jogging) and different pedestrian densities as described in the JRC document 'Design of Lightweight Footbridges for Human Induced Vibrations' [45] is discussed in section 4. In section 5, an analytical calculation example is given for one of the studied bridges, proving the influence of the defined/chosen structural damping ratio on the vertical accelerations, and demonstrating the importance of the human-structure interaction. Finally, the main conclusions are collected in section 6.

\section{Description of web-core sandwich panel footbridges}

A significant portion of current FRP footbridges are so-called web-core sandwich panel bridges. In this bridge type, a flexurally rigid structural element is created through a sandwich construction comprising upper and lower FRP laminate flanges separated by a core material (e.g. PUR foam) $[19,26]$. However, due to the nature of the bridge application, the core material cannot resist all shear forces and concentrated local compressive forces and therefore needs to be complemented with longitudinal and in some cases transverse FRP webs, hence the denomination web-core sandwich panels. For this bridge type, the VARTM [46] technique is used. 
In what follows, ten as-built web-core sandwich panel composite footbridges in the Flanders region of Belgium (Table 1) are shortly introduced. In all cases, the FRP material consists of glass fibre reinforcement embedded in a thermoset matrix, usually polyester.

Table 1: Overview of the tested GFRP web-core footbridges in the Flanders region [23]

\begin{tabular}{cccccc}
\hline No. & Location & Abbr. & $\begin{array}{c}\text { Useful Width, } \\
\mathbf{B}_{\text {use }}[\mathbf{m}]\end{array}$ & $\begin{array}{c}\text { Length(s), } \\
\mathbf{L}[\mathbf{m}]\end{array}$ & $\begin{array}{c}\text { Surface area, } \\
\mathbf{A}\left[\mathbf{m}^{\mathbf{2}} \mathbf{]}\right.\end{array}$ \\
\hline 1 & Bruges & BRG1 & 4.0 & $18.0-8.0-14.9$ & 163.60 \\
2 & Bruges & BRG2 & 4.0 & $17.6-8.0-15.9$ & 167.60 \\
3 & Maldegem & MAL & 2.4 & 8.6 & 20.52 \\
4 & Ghent & GHE & 2.5 & 17.5 & 43.75 \\
5 & Puurs & PUU & 4.2 & 16.6 & 69.72 \\
6 & Mortsel & MOR & 4.3 & 29.2 & 114.38 \\
7 & Deurne & DEU & 2.8 & $10.0-10.0$ & 56.00 \\
8 & Lille & LIL & 2.5 & 20.3 & 50.75 \\
9 & Tremelo & TRE & 3.0 & 10.3 & 30.90 \\
10 & Galmaarden & GAL & 2.0 & 14.0 & 28.00 \\
\hline
\end{tabular}

\subsection{Canada bridges in Bruges}

Two GFRP footbridges were commissioned by the Upper Scheldt department of the Flemish waterway along the up- and downstream sides of the renovated Canada road bridge, on the west side of Bruges. Constructed in 2019, they are both three span continuous bridges, simply supported at all supports, and have a total length of $40.9 \mathrm{~m}$ and $41.5 \mathrm{~m}$ respectively, making them the longest GFRP bridges manufactured in one piece in the world at the moment of publishing this paper. The width of the bridges is $4 \mathrm{~m}$ and the weight is about 22 tons. The bridges were produced by FiberCore Europe from Rotterdam, the Netherlands, using the InfraCore inside technology and have a GFRP handrail from pultruded profiles with two expansion joints. The GFRP bridges replaced timber bridges that were in poor condition. The low weight of the bridges made it possible to reuse the existing abutments of the previous timber bridge without any structural modification. The bridge was designed for a distributed live load of $5 \mathrm{kN} / \mathrm{m}^{2}$ and a service vehicle (unintended vehicle) of $60 \mathrm{kN}$.

\subsection{Maldegem}

This GFRP footbridge, installed in 2019, connects a newly constructed residential area with a main road. The bridge has a length of $8.6 \mathrm{~m}$, a width of $2.4 \mathrm{~m}$ and is simply supported at the abutments. Due to the low weight of the bridge, few extra costs were required for the foundation.

\subsection{Ghent}

Near the historical fish market in the heart of Ghent, this GFRP bridge takes pedestrians across the canal to the entrance of a restaurant. The bridge was manufactured and installed in 2010, making it one of the first GFRP bridges in the Flanders region of Belgium. On the street side (on the right in Figure 1c), the $17.5 \mathrm{~m}$ long and $2.5 \mathrm{~m}$ wide bridge is supported by two piles in order not to overload the abutment, while the restaurant side of the bridge is attached to the building by means of cantilever brackets. During the design, a distributed live load of $5, \mathrm{kN} / \mathrm{m}^{2}$ was taken into account. Remarkable about this bridge is that it is in private possession.

\subsection{Puurs}

Along railway line 54 Mechelen - Terneuzen, located between Brussels and Antwerp, this GFRP bridge is part of the Bicycle Highway F18, connecting the cities of Mechelen and Sint-Niklaas. The bridge was installed in 2019 and has a useful width of $4.2 \mathrm{~m}$ and a length of $16.6 \mathrm{~m}$. The bridge is 
simply supported on both sides. In the first months following the opening of the bridge, there were complaints from pedestrians regarding the comfort and vibrations of the bridge. As a result, this bridge has been thoroughly analysed in terms of vibrations $[42,47]$.

\subsection{Mortsel}

Commissioned by the Province of Antwerp along Bicycle Highway F11, this footbridge connects the cities of Lier and Antwerp. The bridge was constructed in 2019 and has a length of $29.2 \mathrm{~m}$, a useful width of $4.3 \mathrm{~m}$ and a total weight (including the handrail and surfacing) of 30 tons. The bridge is clamped at both abutments over a length of $1.3 \mathrm{~m}$, resulting in a free span of $26.6 \mathrm{~m}$, making it the GFRP bridge with the longest free span in Belgium. A heavy steel handrail of variable height and an acrylic glass panel have been installed to protect pedestrians from the underlying railway. The bridge was manufactured by Composite Structures from the Netherlands. Due to the low electrical conductivity of the GFRP material, the bridge could be installed closer to the overhead lines of the railway, compared to a steel bridge, without interfering eddy currents. The double-sided clamping also ensures smaller deflections and therefore a slimmer cross-section.

\subsection{Deurne}

Constructed in 2019, this bridge is a two-span continuous GFRP footbridge with a total length of $20 \mathrm{~m}$ and a width of $2.8 \mathrm{~m}$. The intermediate support is located in the middle of the bridge. In addition to the bridge deck, the handrail was also made of GFRP material, which is attached to the bridge deck by means of steel bolts. The bridge connects a new development project (residential area and park) to the main street and is also suitable for carrying an emergency vehicle.

\subsection{Lille-Kasterlee}

This GFRP bicycle bridge over the Aa river is part of the bicycle link along the N134 Lille-Kasterlee and was commissioned by the municipality of Lille and installed in 2019. The bridge was prefabricated by FiberCore Europe, is simply supported on both sides and has a length of $20.3 \mathrm{~m}$ and a useful width of $2.5 \mathrm{~m}$.

\section{$2.8 \underline{\text { Tremelo }}$}

Commissioned by the Flemish waterway department and produced by FiberCore Europe in 2018, this GFRP footbridge has a length of $10.3 \mathrm{~m}$ and a useful width of $3 \mathrm{~m}$. It is simply supported on both sides and was designed for a uniformly distributed live load of $5 \mathrm{kN} / \mathrm{m}^{2}$.

\subsection{Galmaarden}

Completed in 2019, this GFRP pedestrian and cyclist bridge in the Baljuwpark has a length of 14 $\mathrm{m}$ and a width of $2 \mathrm{~m}$. It is simply supported on both sides and is part of a project related to raising the dikes to limit flooding in the region.

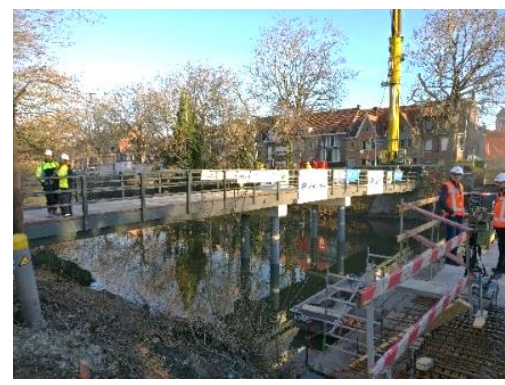

a) Upstream Canada bridge in Bruges

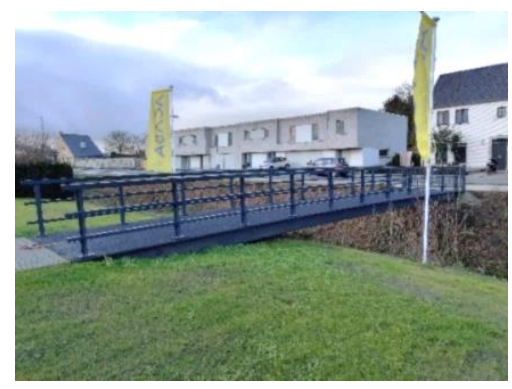

b) Maldegem

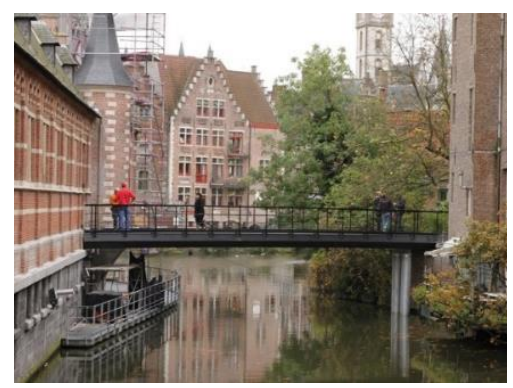

c) Ghent 


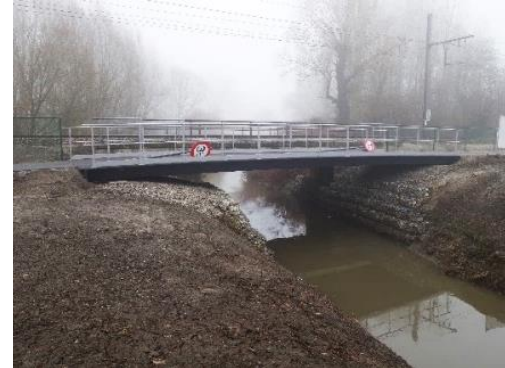

d) Puurs

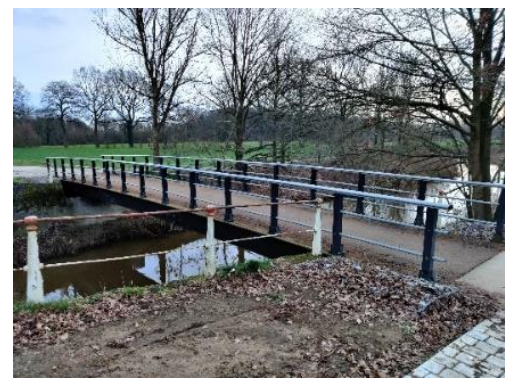

g) Lille

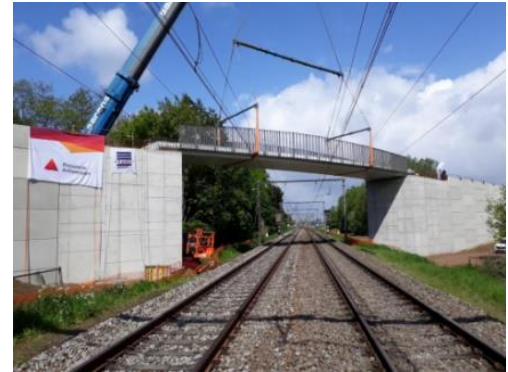

e) Mortsel

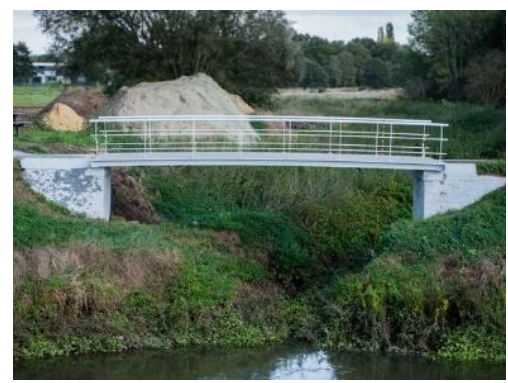

h) Tremelo

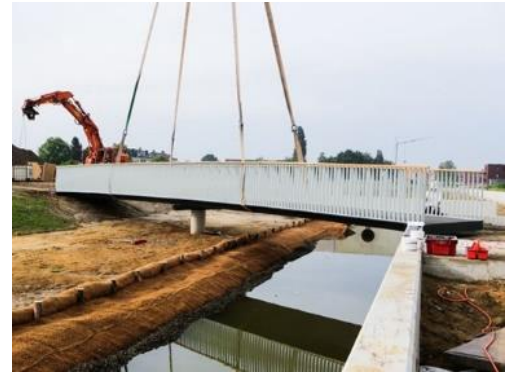

f) Deurne

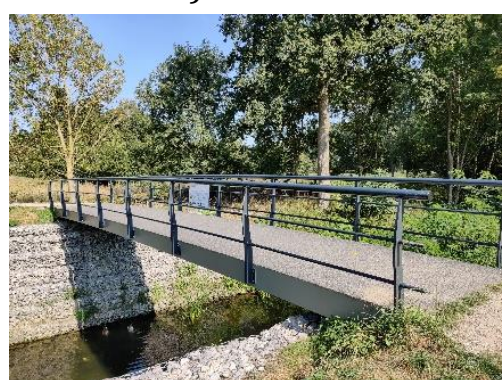

i) Galmaarden

Figure 1: Studied bridges in the Flanders region of Belgium

\section{Modal testing and parameter identification of web-core sandwich footbridges}

In this section, the VibSensor smartphone application used during the tests and the measurement methods will be described, after which the most important results will be presented in relation to the first natural flexural frequency and the damping ratio.

\subsection{VibSensor based smartphone accelerometer data collection}

The VibSensor application is used to measure the vibrations and accelerations on the GFRP footbridges. VibSensor is a freely available application for Android and IOS smartphones released by Now Instruments [44]. It makes it possible for users to easily collect, analyse and export acceleration data from the familiar environment of the smartphone. In addition, this application makes it possible to collect data with a large number of 'sensors' at only a fraction of the cost normally associated with measuring acceleration of civil engineering structures [48-51]. The accelerometer present in the smartphone, measures the acceleration along three main axes of the device. By convention, the axes are labelled as shown in Figure 2. During the tests, the smartphones for measuring the vibrations are placed with the $\mathrm{X}$-axis in the longitudinal direction and consequently the $\mathrm{Y}$-axis in the transverse direction of the bridge.

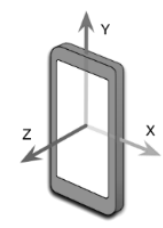

Figure 2: Main axes of the accelerometer in the device [44]

The raw accelerometer data contains the effects of gravity plus any other accelerations the device may be experiencing. In the collection and analysis of the data, this data is split into slowly varying tilt and quickly varying vibrations.

Tests using the VibSensor application on a shaking table performed by Castellanos-Toro et al. [52] have shown that modern smartphones are suitable for engineering tasks such as dynamic structural monitoring. However, laboratory calibrations are still required to ensure the correct 
functioning of the measurement instrument and the software used for the collection of the vibration data. Other research by Cahill et al. [53], which compared different software for the analysis of vibration data, shows that many apps (including VibSensor) can be used to investigate the dynamic response of footbridges, stairs or floors. In addition, some of the mobile devices used during the tests and the VibSensor application were compared with PCB 393B04 seismic sensors $[54,55]$ in the Ghent University lab by the authors. These tests showed again that mobile devices in combination with the VibSensor application give an excellent correlation to the data obtained from the PCB sensors.

For the collection of the vibration data, a timed acquisition of 60 seconds with a varying delay for the different tests and a high frequency range of acquisition were chosen. The "high" range collects at the maximum rate supported by the device, and allows the analysis of vibrational frequencies between 0.03 and $50 \mathrm{~Hz}$. Each data acquisition consists of raw, time-stamped acceleration data that is automatically saved to a database that allows later viewing, analysis and exporting. The report of VibSensor contains a summary of the data collection together with the data acquisition rate information. In the case of the heel and excitation tests, a data acquisition rate of $102.6 \mathrm{~Hz}$ has been used. The report contains a plot, allowing interactive viewing of four types of data, namely the power spectrum, the vibrations, the tilt and the raw unmodified accelerometer data from the device. The power spectrum (PSD) is calculated from $0 \mathrm{~Hz}$ to the Nyquist frequency and the units are $\mathrm{m}^{2} / \mathrm{s}^{3}$. The vibration data consists of the raw accelerometer data, which is high-pass filtered to emphasize vibration. The roll-off frequency in high frequency mode is $1 \mathrm{~Hz}$. Lastly, the tilt contains the raw accelerometer data low-pass filtered to emphasize tilt. The roll-off frequency is the same as for the vibrations.

\subsection{Heel and excitation test}

The heel test (HT) is a very simple and easy to perform test in which one person, also referred to as the operator, causes a vibration at a predefined location on the bridge. The operator will first stand on the tips of their toes, after which they drop onto their heels to cause an impact on the upper flange of the bridge. Since the weight of the person and the impact height remain constant during the different tests, the impact energy will also be roughly constant, making a good comparison between different measurements on the same bridge possible. During a measurement, multiple impacts will be performed with an interval period of 10 seconds, resulting in six quasi-constant vibrations that can be analysed. The test is therefore very easily reproducible and can be performed with a minimum of resources.

In the excitation test (ET), an attempt will be made to excite the bridge according to the first natural flexural frequency. Based on the results of various heel tests performed on the same bridge, an estimation can be made of the first natural flexural frequency of the bridge loaded with one person. This first natural flexural frequency in Hertz is converted into a number of beats per minute (BPM) which will be entered into a metronome. Afterwards, one person will cause a vibration in the middle of the bridge's longest span by bending through their knees according to the calculated number of BPM. It is very important that the feet/heels remain on the surface of the bridge during the execution of this test, since otherwise an impact on the bridge is induced, which causes a disturbance of the signal of the vibration.

The disadvantage of this method is that it cannot be used for relatively stiff bridges, since they will have a high first natural flexural frequency, as a result of which it is no longer possible for a person to produce the necessary number of BPM. In this case, it is still possible to cause an excitation at half the first natural flexural frequency/BPM, i.e. the second harmonic. However, if the tested bridge has a high structural damping ratio, the vibration will diminish very quickly and not enough energy is added to the bridge to bring it into excitation. Energy will be added to the bridge by one person until a maximum vertical acceleration of the bridge is achieved, after which the bridge is allowed to vibrate on its own carrying one person. 
Furthermore, it should be noted that test results from the HT and ET are related to the operatorstructure system, in addition to the structure itself $[35,56,57]$. The presence of the operator to apply the vibration imposes an obvious influence on the dynamic properties of the GFRP footbridge, since the first natural flexural frequency of this system is close to the frequency of the human body. This mechanism can lead to various modifications of the dynamic properties of the operator-structure system, including the increase or decrease of natural frequencies, increase or decrease of damping ratios, and even the appearance of new modes $[6,30,34,58]$.

In both tests, two measuring instruments will be used to record the vibrations of the GFRP footbridges, where one measuring instrument is always placed on MP3 and the other is alternately placed on another measuring point during the tests. In order to get an accurate picture of the vibration of the entire bridge, a measuring grid will be established. The measuring grid consists of five measuring points along the centre line in the longitudinal direction of the bridge (i.e. at 0.5 $\mathrm{m}$ from both end supports and at $25 \%, 50 \%$ and $75 \%$ of the length of the bridge). The same grid is used for the positioning of the operator. Figure 3 gives a graphical representation of the measuring grid used for single span GFRP bridges.

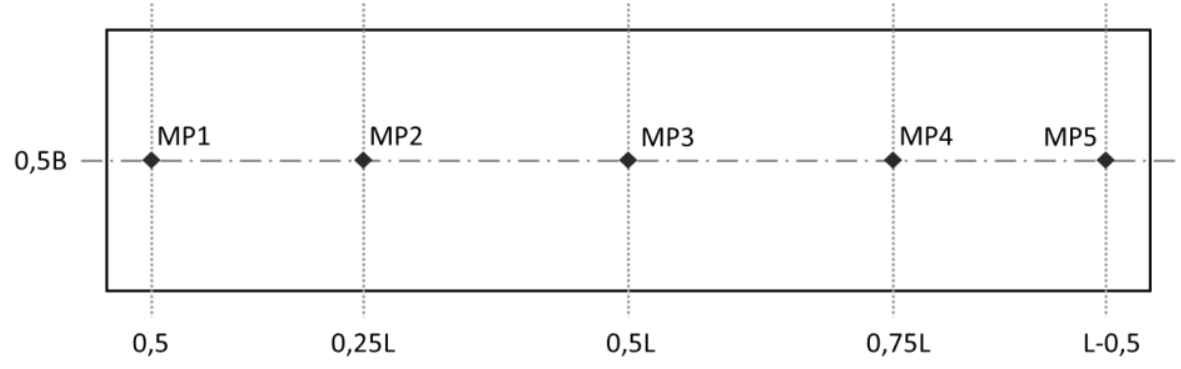

Figure 3: Top view of the measuring grid and naming of the measuring points for the heel and excitation test

For bridges with multiple spans, the above-mentioned measuring grid will be used for the longest span and MP5 will be moved up so that it is above the intermediate support point. Furthermore, extra measuring points will be added in the middle of each span starting from the number 6 .

\subsubsection{First flexural frequency}

\subsubsection{Measured first natural flexural frequency in heel and excitation tests}

For the determination of the first natural flexural frequency of the GFRP web-core footbridges, the values of the power spectrum obtained directly from the VibSensor application from the heel tests are used. Since the outcome of the first natural flexural frequency of the heel tests is used as the basis for applying the vibration in the excitation test, the first natural flexural frequency in the excitation test can only be determined from the free decay of the vibration at the end of the test, the results of which are shown in Table 2 and Figure 4. Further elaboration of the determination of the free decay in the excitation test is given in section 3.2.2.2.

The frequency with the highest PSD is equal to the first natural flexural frequency of the bridge. Since a maximum jogging frequency of $3.5 \mathrm{~Hz}$ is set in the JRC document, an interval of $0 \mathrm{~Hz}$ to double the maximum jogging frequency $(7 \mathrm{~Hz})$ will be set for the determination of the first natural flexural frequency of the GFRP bridges. This interval takes into account the possibility that the second harmonic of the jogging load is able to excite the bending modes of the bridge [47]. Table 2 provides an overview of the average first natural flexural frequencies for the different spans of the tested bridges based on the heel and excitation tests and the coefficient of variation on the set of values of the different measurements. 
Table 2: Mean first natural flexural frequency and coefficient of variation for the heel and excitation test for the considered GFRP web-core footbridges

\begin{tabular}{ccccc}
\hline & \multicolumn{2}{c}{ HT } & \multicolumn{2}{c}{ ET } \\
\cline { 2 - 5 } Location (span) & $\begin{array}{c}\mathbf{f}_{\mathbf{0} \text {,Avrg. }} \\
{[\mathbf{H z}]}\end{array}$ & $\begin{array}{c}\text { COV } \\
{[\%]}\end{array}$ & $\begin{array}{c}\mathbf{f}_{\mathbf{0} \text {,Avrg. }} \\
{[\mathbf{H z}]}\end{array}$ & $\begin{array}{c}\text { COV } \\
{[\%]}\end{array}$ \\
\hline BRG1 $(18.0 \mathrm{~m})$ & 5.23 & $2.78 \%$ & - & - \\
BRG1 $(15.6 \mathrm{~m})$ & 6.52 & $0.08 \%$ & - & - \\
BRG2 (17.6 m) & 5.21 & $0.04 \%$ & - & - \\
MAL & 4.54 & $4.10 \%$ & 4.44 & $9.00 \%$ \\
GHE & 4.91 & $0.12 \%$ & 4.78 & $6.68 \%$ \\
PUU & 3.81 & $0.07 \%$ & 3.79 & $2.61 \%$ \\
MOR & 3.91 & $0.08 \%$ & 3.90 & $0.64 \%$ \\
DEU (10.0 m) & 5.70 & $2.48 \%$ & 5.62 & $4.40 \%$ \\
LIL & 4.81 & $0.06 \%$ & 4.81 & $0.71 \%$ \\
TRE & 5.19 & $3.20 \%$ & 5.36 & $5.02 \%$ \\
GAL & 5.19 & $3.21 \%$ & 5.27 & $4.43 \%$ \\
\hline Average & & $\mathbf{1 . 4 7 \%}$ & & $\mathbf{4 . 1 9 \%}$ \\
\hline
\end{tabular}

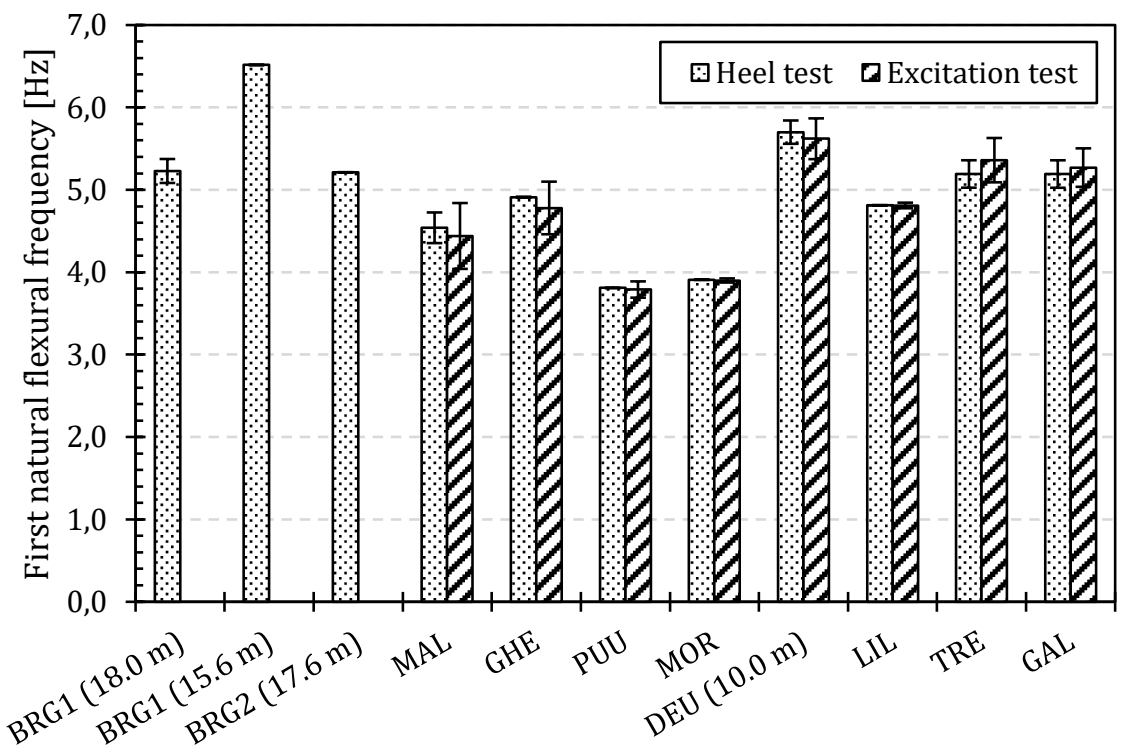

Figure 4: Mean first natural flexural frequency from the heel and excitation test for the considered GFRP webcore footbridges

The results show that neither the testing method (i.e. heel or excitation test) nor the location of the induced vibration has an influence on the value of the first natural flexural frequency. The former can be deduced from the small differences between the results of both tests. The latter can be deduced from the relatively low average coefficient of variation for the heel tests of $1.47 \%$.

Table 2 clearly shows that the first natural flexural frequency of the various GFRP footbridges varies greatly with many factors, such as span, width and depth of the bridge, as well as its support conditions and degree of hyperstaticity. However, it can be concluded that the first natural flexural frequencies of the studied GFRP footbridges are in a range of 3.8 to $6.5 \mathrm{~Hz}$.

No values for the first natural flexural frequency on the basis of the excitation test are included in Table 2 for the upstream and downstream Canada bridges in Bruges, as the weight of the bridges did not allow them to be excited by means of only one person. 


\subsubsection{Measured first natural flexural frequency under pedestrian stream}

Table 3 and Figure 5 are composed of vibration data obtained from comfort analysis tests, described in section 4 . Table 3 gives general information concerning the first natural flexural frequency along the length of the bridge in Tremelo, Ghent, Puurs and Mortsel and this with a pedestrian load of $0.5 \mathrm{P} / \mathrm{m}^{2}$ (traffic class 3, further abbreviated as TC3) [45], while Figure 5 shows the evolution of the first natural flexural frequency as a function of the relative length along the bridge's centreline for the considered bridges. It is clear that the first natural flexural frequency remains roughly the same over the length of the bridge, with a variation from the maximum to the minimum value between $3.3 \%$ and $7.6 \%$.

The difference between the values in Table 2 and the mean values in Table 3 can be related to the difference in load. In the former case one person will cause the vibration, while in the latter case a pedestrian density of $0.5 \mathrm{P} / \mathrm{m}^{2}$ is present on the bridge deck. It is clear that the addition of nonstructural mass, in this case the extra pedestrian load, will cause a decrease in the first natural flexural frequency.

Table 3: General information of the first natural flexural frequency of the comfort analysis test with a pedestrian density of $0.5 \mathrm{P} / \mathrm{m}^{2}$

\begin{tabular}{lcccc}
\hline & Tremelo & Ghent & Puurs & Mortsel \\
\hline Mean [Hz] & 4.70 & 4.54 & 3.18 & 3.74 \\
Coefficient of variation & $6.27 \%$ & $6.31 \%$ & $4.47 \%$ & $7.13 \%$ \\
Minimum [Hz] & 4.56 & 4.47 & 3.10 & 3.54 \\
Maximum [Hz] & 4.92 & 4.62 & 3.22 & 3.82 \\
Min.-Max. COV & $7.63 \%$ & $3.31 \%$ & $3.90 \%$ & $7.51 \%$ \\
\hline
\end{tabular}

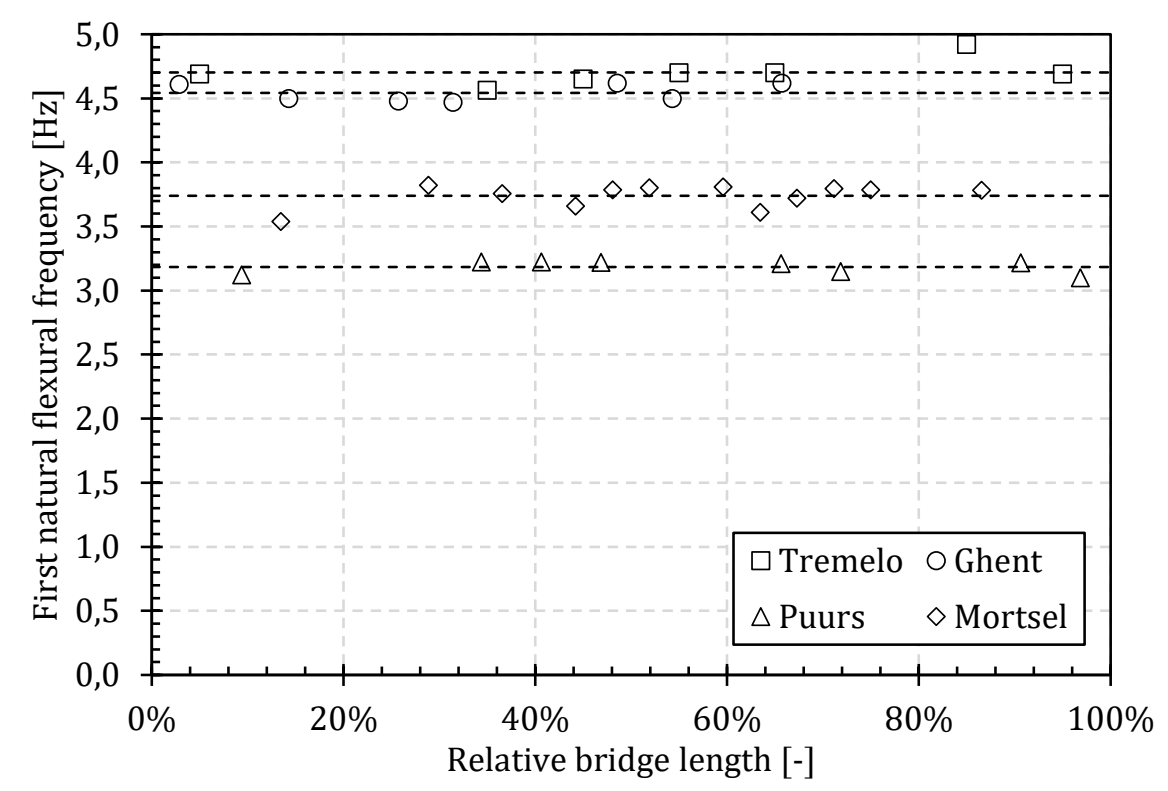

Figure 5: First natural flexural frequency as a function of the relative bridge length for a pedestrian load of 0.5 $\mathrm{P} / \mathbf{m}^{2}$ (TC3)

From Table 2 and Table 3 it can be deduced that the natural frequency in the presence of a pedestrian flow of TC3 on the bridge deck will decrease by $9.45 \%, 7.51 \%, 16.43 \%$ and $4.34 \%$ for respectively the bridges in Tremelo, Ghent, Puurs and Mortsel.

\subsubsection{Expected first natural flexural frequency and implications for comfort}

A good agreement between the calculated value of the first natural flexural frequency under pedestrian traffic and the measured value is crucial in the comfort analysis of the GFRP web-core 
footbridge as defined in EC1990 [59] and the Dutch guideline CUR96:2019 [60]. In both cases, a limit value of the first natural flexural frequency will be assumed above which the comfort analysis becomes redundant.

EN 1990 - A2.4.3.2 pedestrian comfort criteria (for serviceability) [59] states that a verification of the comfort criteria is required for footbridges subjected to pedestrian traffic if the fundamental frequency is less than $5.0 \mathrm{~Hz}$ [59]. Among structural designers, the $5 \mathrm{~Hz}$ limit is considered most often for non-FRP structures since it ensures that resonance is avoided for the first two harmonics for walking (i.e. 1.25-2.5 Hz and 2.5-5.0 Hz, respectively), which contain the highest excitation energy. However, for the design of FRP structures, EUR 23984 EN guideline for the design of Lightweight Footbridges for Human Induced Vibrations [45] and the Dutch guideline CUR96:2019 for the design of Fibre-reinforced polymers in architectural and civil engineering supporting structures [60] propose Figure 6 to determine a reduction coefficient as a function of the first natural flexural frequency, which is applied to the maximum vertical acceleration in order to obtain the design vertical acceleration for the comfort analysis. To take into account a variation in the first natural flexural frequency of the bridge (for example due to model uncertainties with regard to mass, clamping effects, handrails, etc.) which would still lead to discomfort, a conservative requirement for the reduction coefficient of 0.25 was imposed in the CUR96:2019 for the frequencies between $2.2 \mathrm{~Hz}$ and $3.4 \mathrm{~Hz}$, marked with the red dashed line. Lastly, resonance and discomfort will not be expected for natural frequencies above $4.6 \mathrm{~Hz}$.

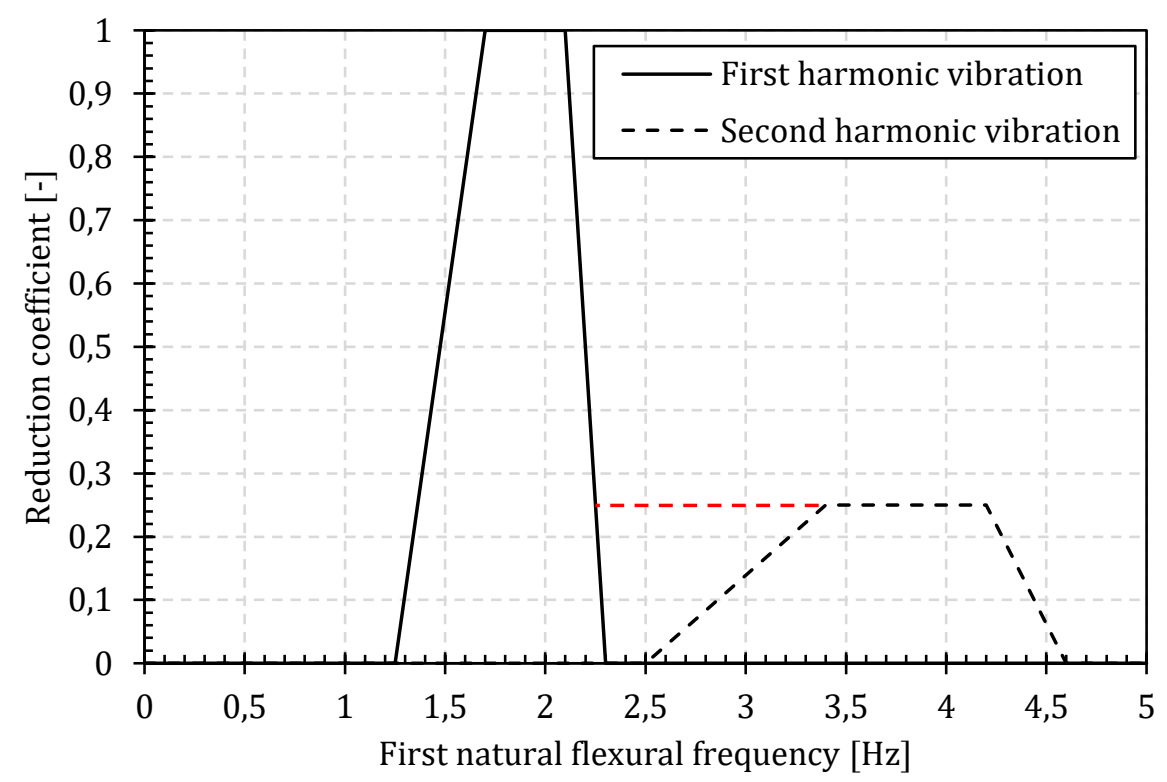

Figure 6: Reduction coefficient for pedestrian traffic as a function of the first natural flexural frequency [60]

A first natural flexural frequency higher than $4.6 \mathrm{~Hz}$ ensures that resonance in the first two walking harmonics is avoided. From Table 2 and Figure 6, it follows that in the design stage, no vertical accelerations and discomfort are expected for seven out of ten bridges, in Bruges, Ghent, Deurne, Lille, Tremelo and Galmaarden. However, further in this paper it will be shown that, with the currently applied design methods, a first natural flexural frequency-based design to ensure sufficient comfort does not guarantee the overall comfort of the GFRP web-core footbridge in reality.

\subsubsection{Damping ratio}

The damping ratio will be determined through the heel and excitation test on the basis of the acceleration data obtained from the VibSensor application. Different processing techniques will be applied to the acquired data. 


\subsubsection{Heel tests}

Figure 7 shows the vibration data in the three main directions at MP3 from the first heel test on the GFRP footbridge in Maldegem. It is clear that the vibrations in the horizontal $\mathrm{X}$ and $\mathrm{Y}$ directions are limited in value, partly due to the centric application of the impacts on the bridge. Hence, only the vibration in the $\mathrm{Z}$ direction will be considered and the damping ratio will be determined for the vertical accelerations.

The vertical vibrations will first be subjected to a second order bandstop Butterworth filter [6164] with a lower and higher cut-off frequency of respectively $0.5 \mathrm{~Hz}$ below and $0.5 \mathrm{~Hz}$ above the first natural flexural frequency of the respective measurement on the bridge. The sample rate is equal to the sample frequency of the VibSensor application [44] for the relevant measurement. In addition, a Gaussian-weighted moving average smoothing [65-67] will also be applied to the resulting data with a window length of 10 ( 5 elements backward and 5 elements forward). Both operations will remove second order effects and extreme values from the vibration data and lead to more truthful damping ratio values in the calculation.

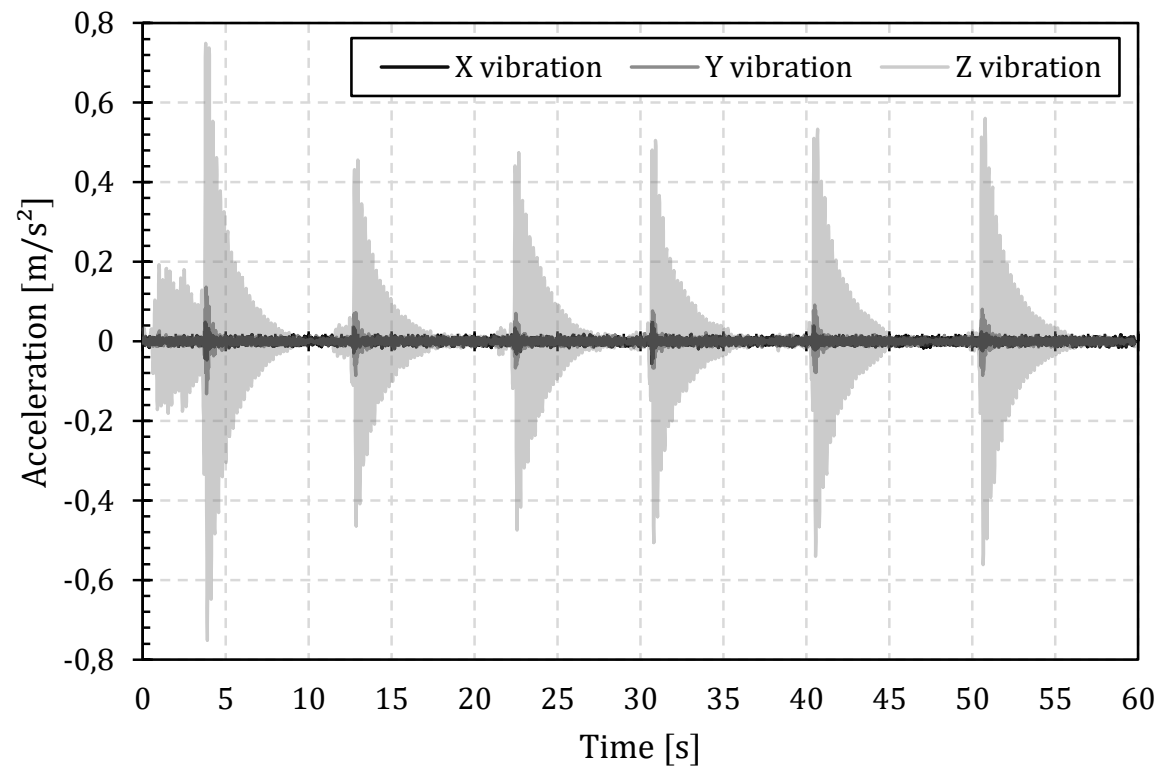

Figure 7: Raw vibrations in the three main directions at MP3 for a heel test in Maldegem

After filtering and smoothing the data, a MATLAB script developed by the author will be used to analyse the vibration data. Here, the data will first be split into individual vibrational responses in the time domain, after which the logarithmic decrement and the associated damping ratio of the positive and negative overshoots will be determined for the different individual vibrations. A cutoff of 1.2 seconds to disregard any unwanted vibrations at the start of the measurements will be applied. Moreover, a limit value of $50 \%$ the maximum vertical acceleration of the concerning measurement and an operation to detect the abrupt changes in the data will be used to determine the number of vibrations in the data in the time domain and split the data into the individual vibrations. Subsequently, the positive and negative overshoots will be determined until a cut-off amplitude of 5\% the start amplitude of the concerning vibration is reached or until 25 points have been recorded, whichever occurs first. This limiting boundary for the cut-off amplitude was set to distinguish between the actual vibration analysed and the noise occurring during the measurement in the intervening period between successive impacts.

On the basis of the positive and negative overshoots of the vertical acceleration of one individual vibration and the following formulas, it is possible to determine the logarithmic decrement $\delta$ and the damping ratio $\zeta$ from the vibration. Here, the value of $n$ will depend on the number of cycles that are considered. 


$$
\begin{gathered}
\delta=\frac{1}{n} \ln \frac{x(t)}{x(t+n T)} \\
\zeta=\frac{1}{\sqrt{1+\left(\frac{2 \pi}{\delta}\right)^{2}}}
\end{gathered}
$$

Figure 8 shows the third vibration out of Figure 7 and visualises the positive and negative overshoots of the vertical acceleration and the corresponding logarithmic decrement.

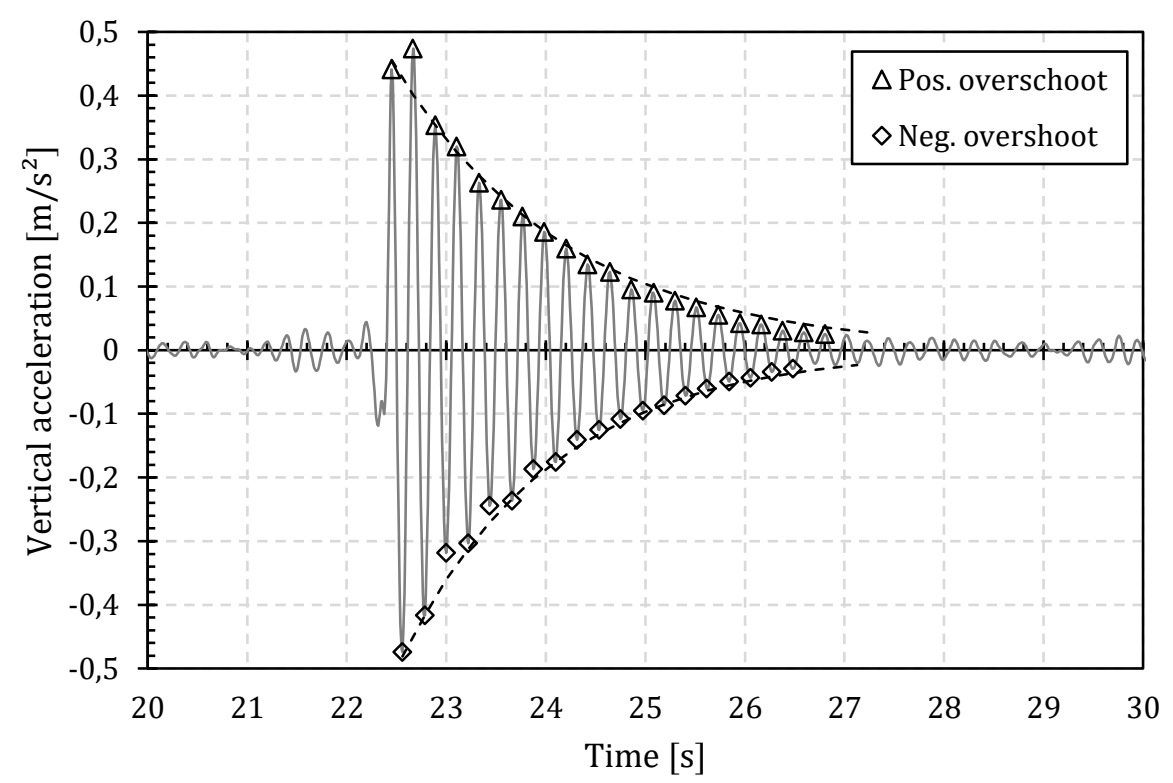

Figure 8: Logarithmic decrement of the third vibration during the heel test in Maldegem

On the basis of the values obtained for the positive and negative curve of the individual vibrations of each measurement, it is possible to calculate an average and standard deviation for the damping ratio of the relevant vibration. This procedure is repeated for all measurements taken at the various measurement points and will make it possible to analyse the damping ratio for different load situations and measurement locations.

The following graphs in Figure 9 and Figure 10 give an overview of the average damping ratio for the heel test with one person and two people respectively for the different GFRP footbridges studied in this paper. Note that not the exact same measurements were made for every bridge. For symmetrical bridges with one span, for example, measurements were only made at the measurement point at $0.25 \mathrm{~L}$ or $0.75 \mathrm{~L}$. In addition, the figures also show the average damping ratio value for the studied bridges by means of a horizontal dashed line. 


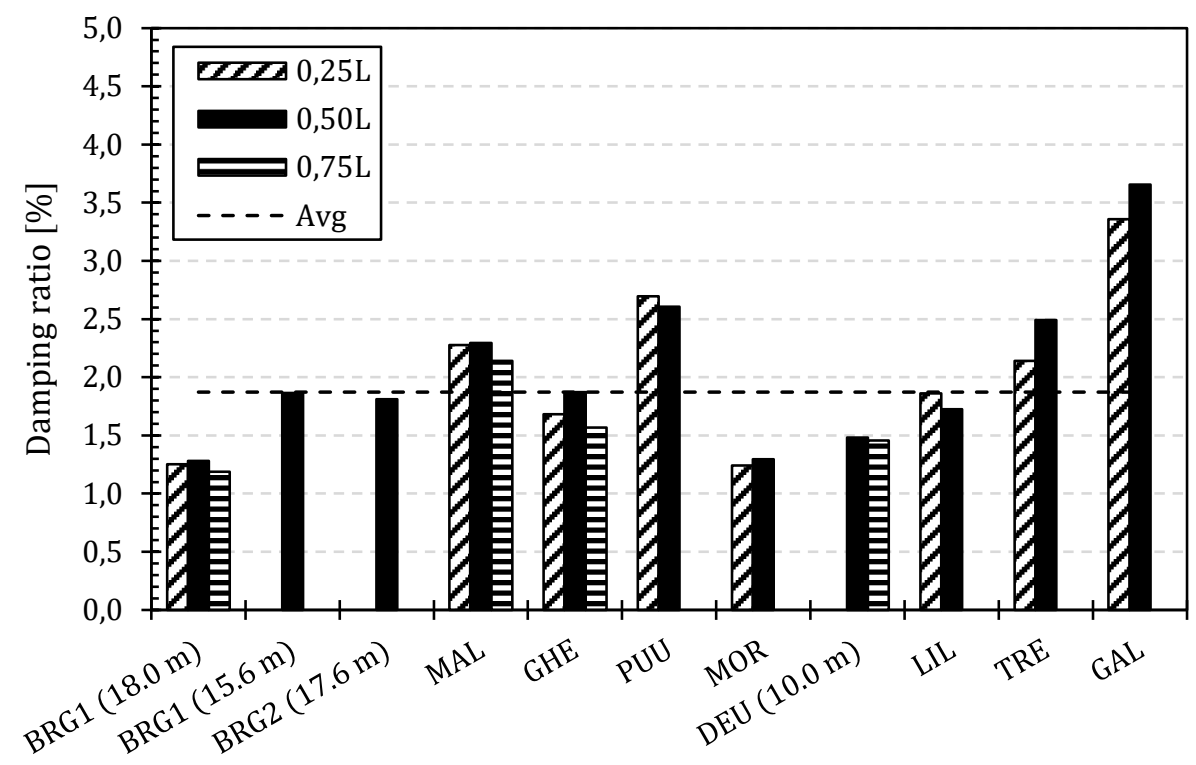

Figure 9: Damping ratio originating from heel tests for the studied GFRP bridges for different lengths and one person

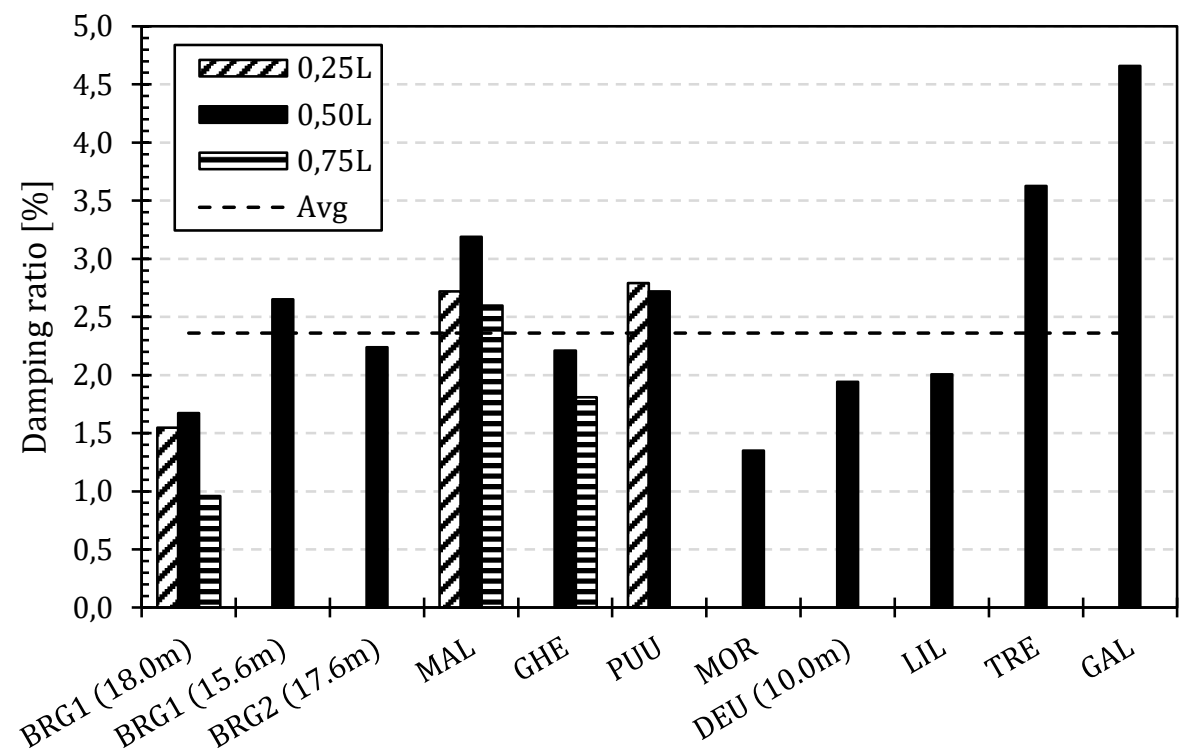

Figure 10: Damping ratio originating from heel tests for the studied GFRP bridges for different lengths and two people

The minimum, maximum and average damping ratios during the heel test with one person at midspan $(0.5 \mathrm{~L}$ ) of the concerning bridges are $1.28 \%, 3.66 \%$ and $1.87 \%$ respectively, while for the test with two people, these values are equal to $1.35 \%, 4.66 \%$ and $2.36 \%$ respectively. From the mean values it is clear that there is a certain operator dependence in the structural damping ratio for GFRP web-core footbridges.

The results are consistent with recent research by Wei et al. [68] which showed that for 10 out of 14 FRP footbridges, damping ratios for the fundamental vertical flexural vibration mode were found between $1.2 \%$ and $2.7 \%$ with outliers of $0.4 \%$ and $7.9 \%$. Compared to the results from Wei et al., the minimum and maximum values in the present study are much closer to the average, without outliers.

As mentioned, a certain increase in the structural damping ratio of the GFRP footbridge is visible if an extra person takes place on the bridge. The percentage increase between the damping ratio 
for a bridge loaded with one person and with two people is shown in Figure 11. The average increase for all studied bridges is also shown by the horizontal dashed line.

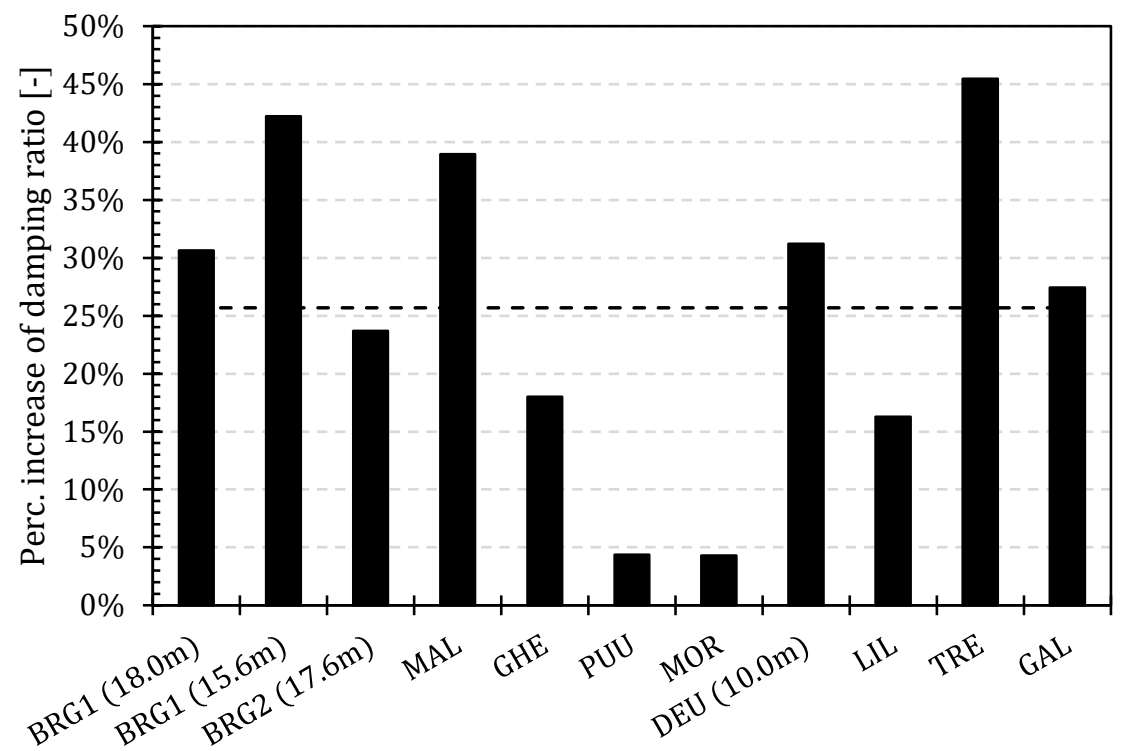

Figure 11: Percentage increase of the damping ratio under a load of 1 person with respect to that under a load of two people

It can be concluded that the structural damping ratio of a GFRP web-core footbridge with two people will already be larger than if the bridge is loaded with one person. The difference in damping ratio is non-negligible with a minimum, maximum and average value of $4 \%, 45 \%$ and $26 \%$ respectively. This clearly indicates that there is human-structure interaction with regard to lightweight GFRP footbridges, even when only adding one or two people.

\subsubsection{Excitation tests}

Figure 12 shows the raw acceleration data at MP3 from an excitation test on the GFRP bridge in Ghent. The vibrations in the $\mathrm{X}$ and $\mathrm{Y}$ directions are negligible and the analysis will only be performed on the vertical $\mathrm{Z}$ vibrations.

The vertical vibrations are also subjected to a second order bandstop Butterworth filter [61-64] with a lower and higher cut-off frequency of $0.5 \mathrm{~Hz}$ below and above the first natural flexural frequency of the respective measurement on the bridge. In addition, a Gaussian-weighted moving average smoothing [65-67] is also applied to the resulting data with a window length of 10 (5 elements backward and 5 elements forward).

For the calculation of the damping ratio, only the free vibration at the end of the test will be considered, observable in Figure 12 from 43 seconds onwards. An amplitude cut-off limit of 5\% with respect to the starting amplitude value of the vibration will be set to allow a distinction between the vibration and the noise occurring due to environmental factors. 


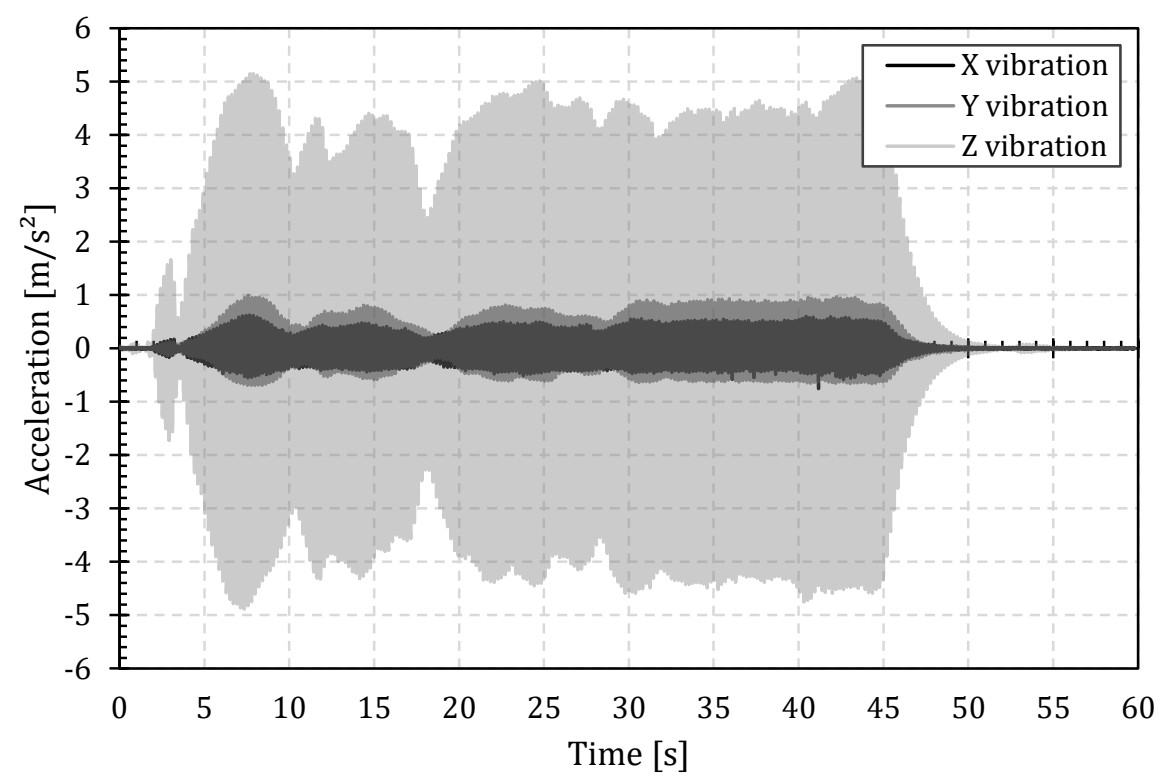

Figure 12: Raw vibrations in the three main directions at MP3 for an excitation test in Ghent

In this analysis, as opposed to the analysis of the heel test, a maximum of 30 overshoot values is chosen, since the amplitude of the vibration in the excitation test is larger in absolute value and the damping of the vibration will last longer. As seen in Figure 13, larger values of the vertical acceleration are obtained during the excitation test, a consequence of adding more energy compared to the heel test.

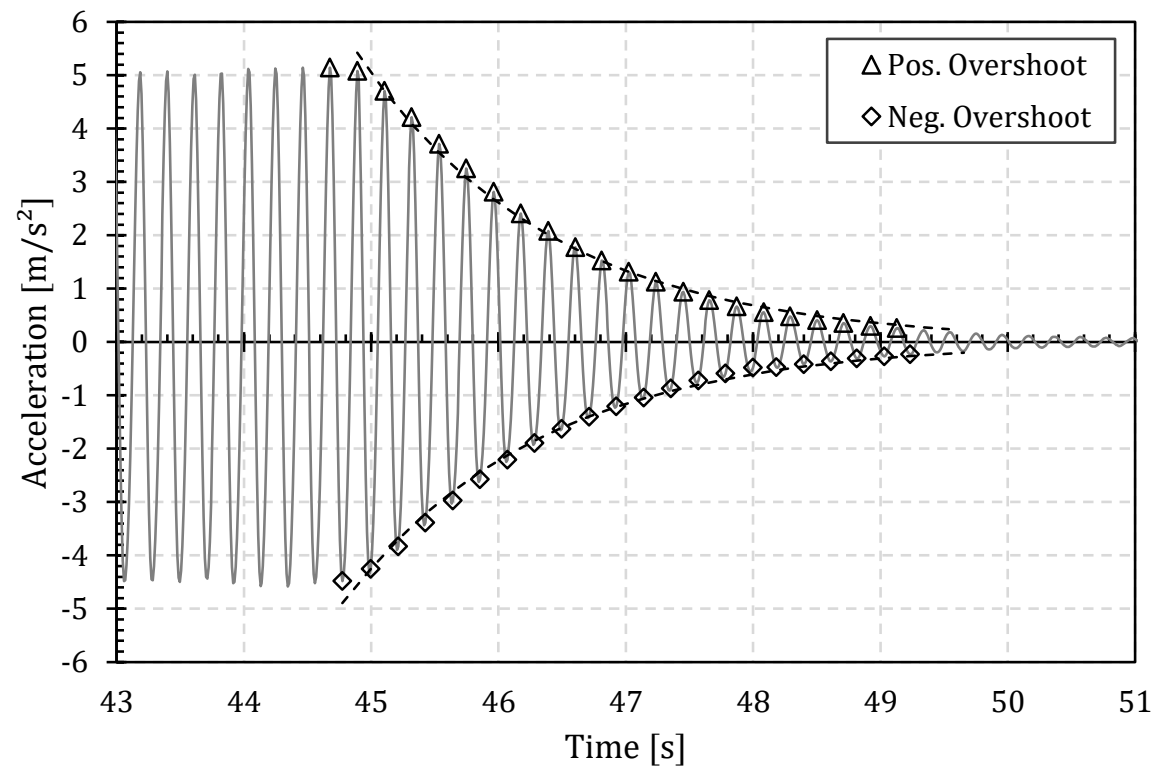

Figure 13: Logarithmic decrement of the vibration during the excitation test in Ghent

A summary of the results for the damping ratio for eight of the studied GFRP footbridges can be found in Figure 14. Since it was not possible to excite the bridges in Bruges with the help of one or two people (an observation for multiple span bridges also described by Wei et al.), they are not included in the graph. For the other bridges, the average values of the damping ratio for one and two people of multiple tests are displayed. In addition, the general averages across all eight bridges of the damping ratio for a bridge loaded with one and two people are displayed, respectively by a dashed line and a dash-dot line. 


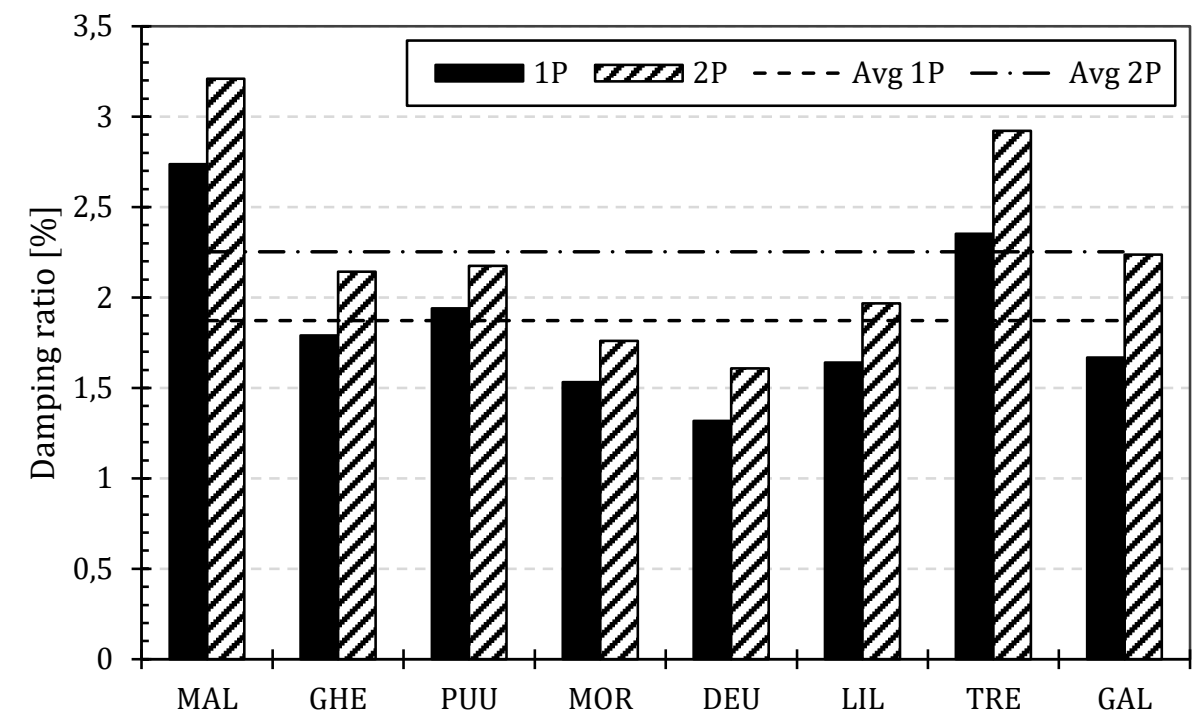

Figure 14: Damping ratio originating from the excitation test for the studied GFRP bridges for one and two people

Figure 14 shows the discrepancy between the values of the damping ratio for the different studied bridges (one and two person tests). The average values of the damping ratio for a bridge loaded with one person and two people are $1.87 \%$ and $2.25 \%$ respectively.

Figure 15 shows the percentage increase in the damping ratio for the studied bridges loaded with one person or two people. As in Figure 11, it can be concluded that there is an increase in the damping ratio with a minimum, maximum and average increase of $12 \%, 34 \%$ and $20 \%$ respectively. This average increase is in line with the earlier conclusion from the heel test with an average increase of about $25 \%$ between the values for one person and two people.

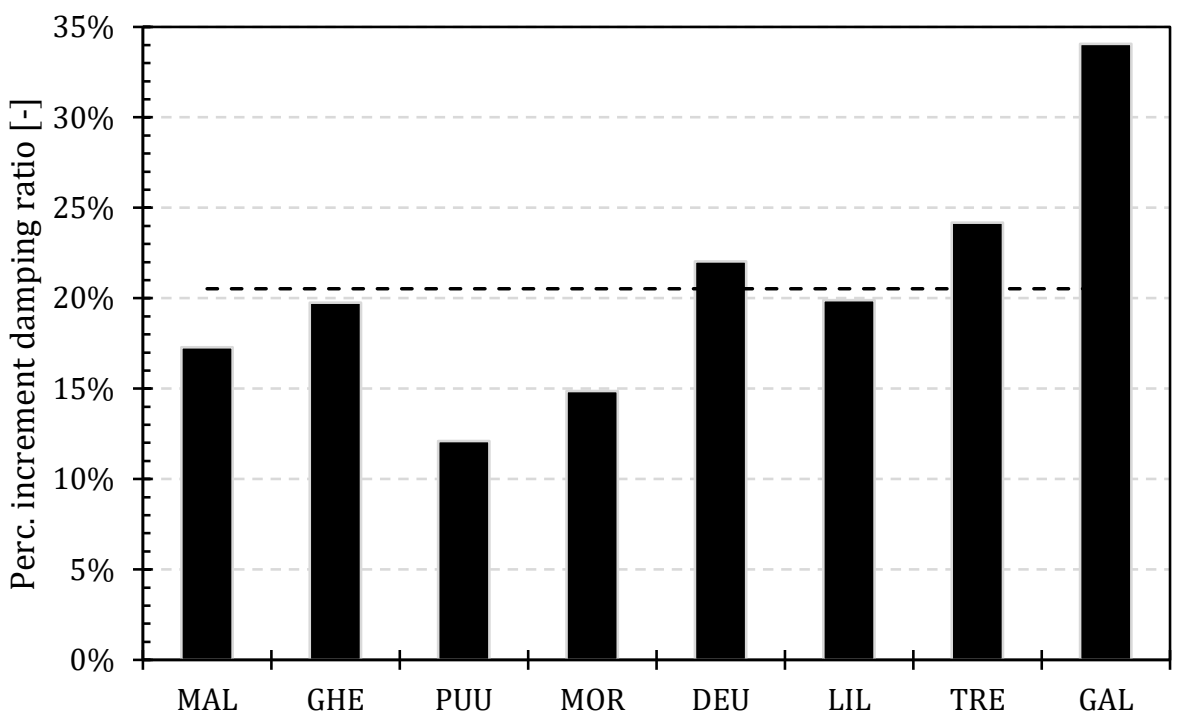

Figure 15: Percentage increase in damping ratio between a GFRP footbridge loaded with one person and two people

Figure 16 shows the evolution of the damping ratio as a function of the ratio of the mass of the one person and two people on the bridge (the operator(s)) to the structural mass of the bridge. The average mass of the people on the bridge during the tests is $70 \mathrm{~kg}$, and the structural weight of the bridge is set to a realistic value of $260 \mathrm{~kg} / \mathrm{m}^{2}$. 


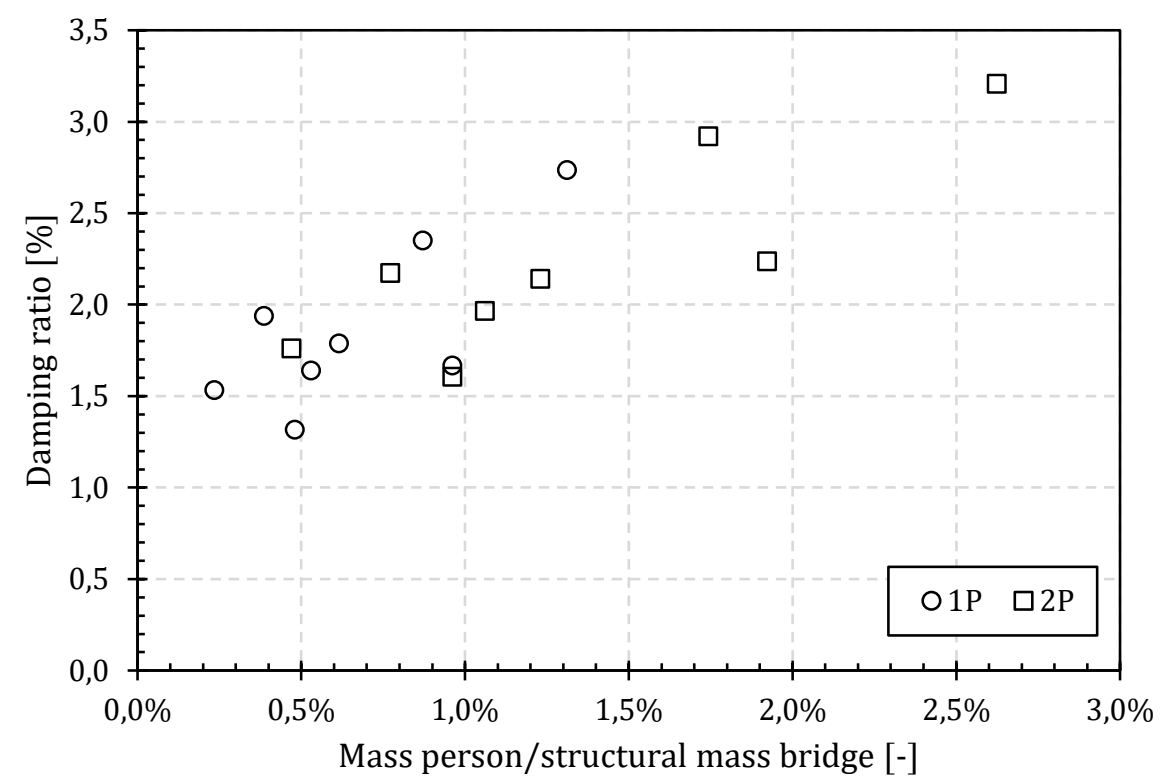

Figure 16: Evolution of the damping ratio as a function of the percentage pedestrians on the bridge deck

A clear increase in the damping ratio is visible with an increasing percentage of people on the bridge. For example, it can be stated that with a person mass to structural mass ratio of about $0,5 \%$ on the bridge deck, the damping ratio is on average $1.7 \%$, while for a percentage weight of about $1.0 \%$, the damping ratio will increase to an average value of about $2.0 \%$. From this, it can be deduced that the presence of the people on the bridge deck has an important influence on the structural damping value of the GFRP web-core footbridge and that there is a certain humanstructure interaction. As stated in the research by Van Nimmen et al. [29,69], the human body will not only induce vibrations but also act as a damper for the vibrations of the bridge $[7,70]$.

\section{Comfort analysis of web-core sandwich footbridges}

From the ten bridges of Table 2, five bridges (i.e. Ghent, Puurs, Mortsel, Deurne and Tremelo) are loaded with varying pedestrian traffic and different load situations. Table 4 shows the different pedestrian densities $d_{T C}$ that will be used during the tests and as defined in the JRC document [45]. The density of the pedestrian traffic is expressed in the number of people present per square meter of bridge surface $\left(\mathrm{P} / \mathrm{m}^{2}\right)$.

Table 4: Pedestrian densities used during the tests as defined in the JRC document

\begin{tabular}{ccc}
\hline Traffic class & $\begin{array}{c}\text { Pedestrian density, } \\
\mathbf{d}_{\text {TC }}\left[\mathbf{P} / \mathbf{m}^{\mathbf{2}}\right]\end{array}$ & Description \\
\hline TC1 & 0.1 & Very weak traffic \\
TC2 & 0.2 & Weak traffic \\
TC3 & 0.5 & Dense traffic \\
\hline
\end{tabular}

Since most bridges are located in an area with little passage, TC1 will correspond to the daily use of the bridge. In this case, people will only sporadically be present on the bridge. In the second case (TC2), it is still possible to walk comfortably and freely on the bridge and overtaking is possible at any time. This situation will occur, for example, at special events. In the last traffic class (TC3), it is still possible to walk freely on the bridge, but overtaking can intermittently be inhibited. This last load case will only occur a few times in the entire lifetime of the GFRP bridge, such as, for example, during the inauguration of the bridge. In addition to the three traffic classes used during the human-induced vibration tests, the JRC document also describes TC4 and TC5. In the TC4 case, the pedestrian traffic on the bridge will be very dense $\left(\mathrm{d}_{\mathrm{TC}}=1.0 \mathrm{P} / \mathrm{m}^{2}\right)$, the freedom of movement on the bridge is restricted, walking will be obstructed and overtaking is no longer 
possible. TC5 on the other hand, will be used for exceptional traffic $\left(\mathrm{d}_{\mathrm{TC}}=1.5 \mathrm{P} / \mathrm{m}^{2}\right)$, walking on the bridge will be considered unpleasant, crowding starts and one can no longer freely choose pace [45].

On the basis of the surface area of the considered bridges, the required number of people during the test can be calculated for the various pedestrian densities and GFRP footbridges. The results are shown in Table 5.

Table 5: Number of people for the human-induced vibration test for different pedestrian densities

\begin{tabular}{|c|c|c|c|}
\hline Location & $\begin{array}{c}\text { TC1 } \\
{\left[0.1 \mathrm{P} / \mathrm{m}^{2}\right]}\end{array}$ & $\begin{array}{c}\text { TC2 } \\
{\left[0.2 \mathrm{P} / \mathrm{m}^{2}\right]}\end{array}$ & $\begin{array}{c}\text { TC3 } \\
{\left[0.5 \mathrm{P} / \mathrm{m}^{2}\right]}\end{array}$ \\
\hline Ghent & 4 & 8 & 20 \\
\hline Puurs & 8 & 15 & 38 \\
\hline Mortsel & 12 & 23 & 58 \\
\hline Deurne & 6 & 11 & 28 \\
\hline Tremelo & 3 & 6 & 16 \\
\hline
\end{tabular}

In total, two different types of human-induced vibrations were considered for the mentioned pedestrian densities, namely under the influence of either free walking or jogging. Hereby the pedestrians will walk or jog for 60 seconds on the bridge in clockwise direction at a freely chosen pace. A total of six measurements will be made for every bridge.

In contrast to the measuring grid used for the heel and excitation test, every meter a measuring point will be provided along the centreline in the longitudinal direction of the bridge during this test. The number of measuring points per bridge therefore depends on the bridge span. Figure 17 shows a graphical representation of the measuring grid used.

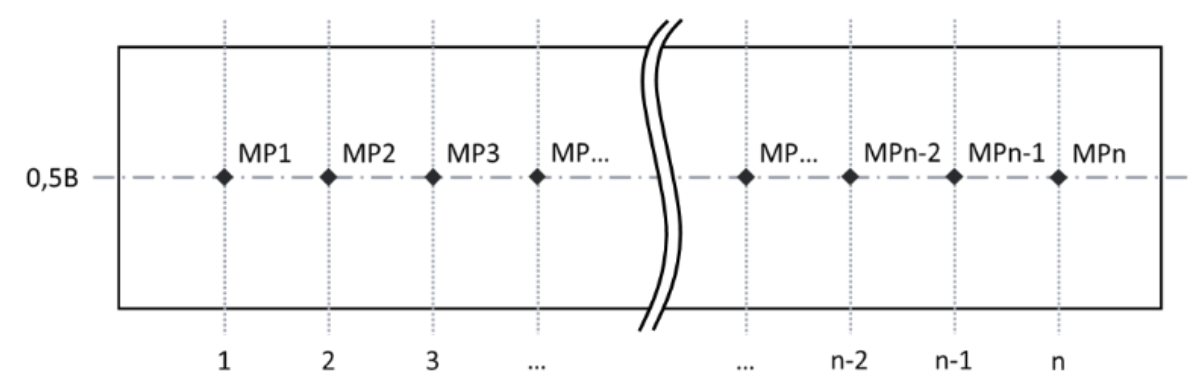

Figure 17: Top view of the measuring grid and designation of the measuring points for the human-induced vibration tests

For bridges with multiple spans, an additional measuring point above the intermediate supports will be added between the standard measuring points along the centreline of the bridge and will be included in the designation of the regular measuring points following the sequence above.

The comfort of the GFRP footbridges is studied for various load situations (i.e. walking and jogging) with varying pedestrian density. The measured vibration data from the VibSensor [44] application in the $\mathrm{Z}$ direction can be directly compared to the requirements for the comfort classes from the JRC document. Figure 18 shows the acceleration along the Z-axis of the bridge in Tremelo for the different traffic classes for walking and jogging respectively. 

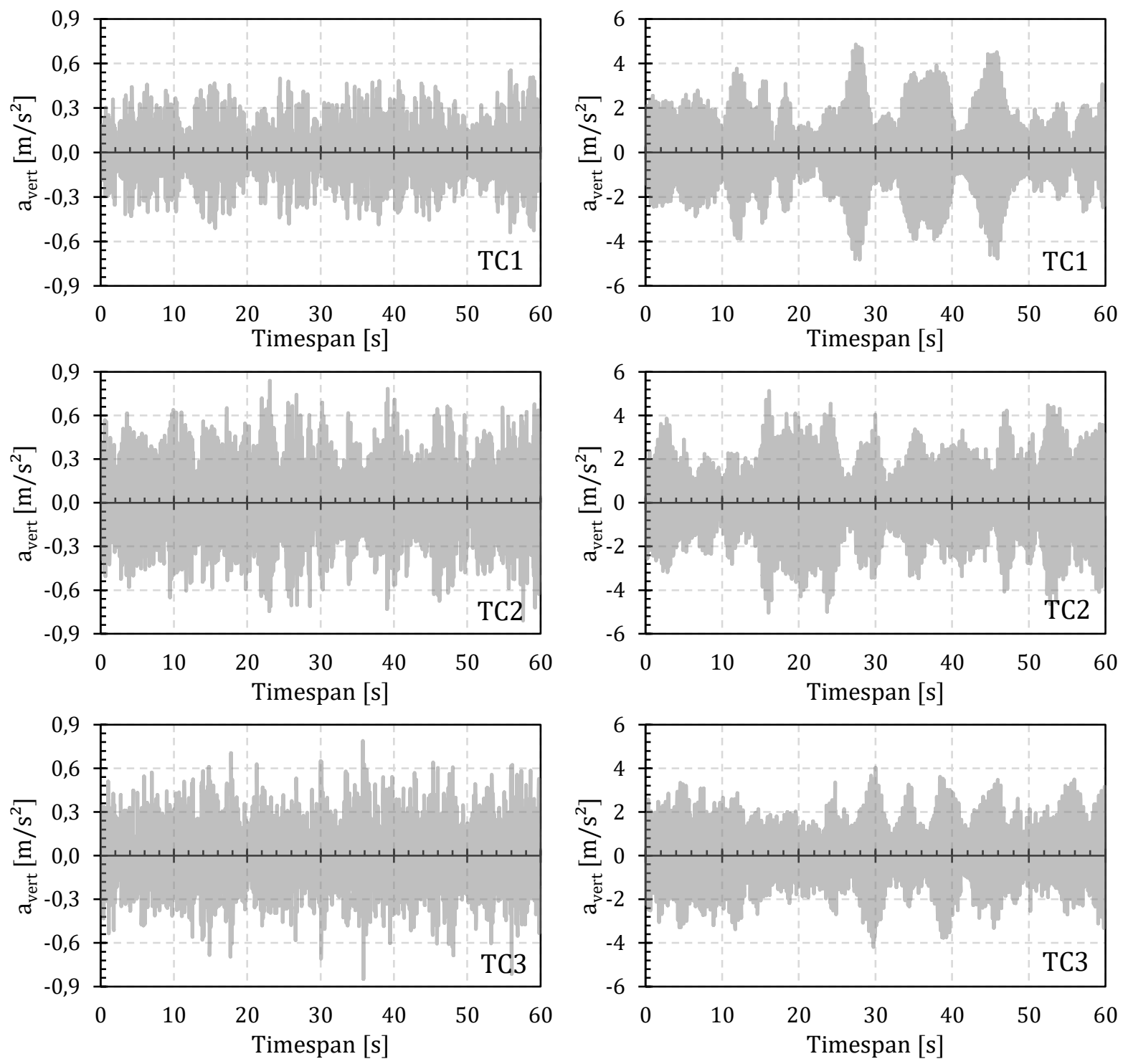

Figure 18: Vertical acceleration while walking (left) and jogging (right) for TC1, TC2 and TC3 on the GFRP footbridge in Tremelo

It is clear that for this bridge, the vertical accelerations in the case of jogging are approximately three times larger than while walking with the same pedestrian density. For the different studied bridges and pedestrian densities, the maximum and root mean square (RMS) values of the maximum acceleration were determined. The results for walking and jogging can be found in Table 6 and

Table 7 respectively.

Table 6: Maximum and RMS value for the $\mathrm{Z}$ accelerations during walking for various pedestrian densities

\begin{tabular}{ccccccc}
\hline \multirow{2}{*}{ Location } & \multicolumn{3}{c}{ MAX $\left[\mathrm{m} / \mathbf{s}^{\mathbf{2}}\right]$} & \multicolumn{3}{c}{ RMS $\left[\mathrm{m} / \mathbf{s}^{\mathbf{2}}\right]$} \\
\cline { 2 - 7 } & TC1 & TC2 & TC3 & TC1 & TC2 & TC3 \\
\hline Tremelo & 0.554 & 0.838 & 0.789 & 0.178 & 0.258 & 0.216 \\
Ghent & 0.505 & 0.547 & 0.757 & 0.178 & 0.166 & 0.219 \\
Puurs & 0.492 & 0.686 & 0.508 & 0.125 & 0.166 & 0.144 \\
Deurne & 0.654 & 0.599 & 0.767 & 0.188 & 0.186 & 0.194 \\
Mortsel & 0.425 & 0.389 & 0.268 & 0.103 & 0.112 & 0.074 \\
\hline
\end{tabular}


Table 7: Maximum and RMS value for the $\mathrm{Z}$ accelerations during jogging for different pedestrian densities

\begin{tabular}{ccccccc}
\hline \multirow{2}{*}{ Location } & \multicolumn{3}{c}{ MAX $\left[\mathrm{m} / \mathbf{s}^{\mathbf{2}}\right]$} & \multicolumn{3}{c}{ RMS $\left[\mathbf{m} / \mathbf{s}^{\mathbf{2}}\right]$} \\
\cline { 2 - 7 } & TC1 & TC2 & TC3 & TC1 & TC2 & TC3 \\
\hline Tremelo & 4.860 & 5.132 & 4.028 & 1.513 & 1.580 & 1.247 \\
Ghent & 1.960 & 1.901 & 2.693 & 0.584 & 0.605 & 0.787 \\
Puurs & 2.381 & 2.127 & 2.878 & 0.474 & 0.559 & 0.706 \\
Deurne & 1.438 & 1.698 & 2.056 & 0.358 & 0.452 & 0.487 \\
Mortsel & 0.849 & 1.153 & 1.232 & 0.203 & 0.274 & 0.334 \\
\hline
\end{tabular}

From both tables it can be concluded that the pedestrian density shows no linear relationship with the magnitude of the vertical vibrations. For example, a pedestrian density of $0.5 \mathrm{P} / \mathrm{m}^{2}$ will not necessarily lead to the largest vertical accelerations. This shows that the human body will add a large amount of damping to GFRP bridges, since the added mass of the pedestrian traffic will be proportionally large with respect to the self-weight of the bridge.

From the maximum and RMS values of the vertical acceleration for the various GFRP footbridges, it can be concluded that in the case of walking, all bridges are in comfort class 1 (CC1, lower than $0.5 \mathrm{~m} / \mathrm{s}^{2}$ ) for most of the time (RMS value), which is the most desirable comfort class, and that they will only rise to comfort class $2\left(\mathrm{CC} 2,0.5 \mathrm{~m} / \mathrm{s}^{2}\right.$ to $1.0 \mathrm{~m} / \mathrm{s}^{2}$ ) for a very short period (MAX value). In the case of jogging, all bridges, except the Tremelo bridge, are in CC2 for most of the time while for short periods this will increase to CC3 $\left(1.0 \mathrm{~m} / \mathrm{s}^{2}\right.$ to $\left.2.5 \mathrm{~m} / \mathrm{s}^{2}\right)$ or even CC4 (higher than $2.5 \mathrm{~m} / \mathrm{s}^{2}$ ).

The results point to the current inability to accurately predict the pedestrian comfort of GFRP web-core footbridges, since human-induced damping is not included in current design guidelines and normative documents. A pedestrian comfort-based design will probably underestimate the actual damping, and lead to overconservative designs. It addition, based on the measured natural frequencies from Table 2, no unacceptable vibrations would be expected under the applied pedestrian traffic classes according to the current standards and guidelines. However, this expectation cannot be supported by the results from these comfort analysis tests.

\section{Comparison of measurements to analytical predictions}

\subsection{Geometry}

In this section, the measured data from the Puurs bridge [23] (section 2.4) is compared to analytical predictions based on CUR96-2019 [60] and the JRC document 'Design of Lightweight Footbridges for Human Induced Vibrations' [45]. Table 8 gives a brief overview of the external geometry of the bridge in question. 


\begin{tabular}{lc}
\hline Properties & Value \\
\hline Bridge length, $\mathrm{L}_{\text {bridge }}$ & $16.60 \mathrm{~m}$ \\
Bridge span, $\mathrm{L}_{\text {span }}$ & $16.20 \mathrm{~m}$ \\
Bridge width, $\mathrm{B}_{\text {bridge }}$ & $4.60 \mathrm{~m}$ \\
Useful width, $\mathrm{B}_{\text {use }}$ & $4.20 \mathrm{~m}$ \\
Depth, hbridge & $0.40 \mathrm{~m}$ \\
Thickness surfacing, $\mathrm{t}_{\text {surf }}$ & $5 \mathrm{~mm}$ \\
Surface area, $\mathrm{A}_{\text {bridge }}$ & $76.36 \mathrm{~m}^{2}$ \\
Structural mass bridge, $\mathrm{m}_{\text {struc }}$ & 7.68 tons \\
Total mass (incl. surfacing), $\mathrm{m}_{\text {tot }}$ & 8.27 tons \\
\hline
\end{tabular}

The bending and shear stiffnesses of the GFRP web-core footbridge in Puurs are calculated through the classical laminate theory (CLT) :

$$
\mathrm{EI}_{\mathrm{x}}=178.68 \mathrm{MNm}^{2} \quad \mathrm{GA}_{\mathrm{xy}}=262.15 \mathrm{MN}
$$

\subsection{First natural flexural frequency}

For the calculation of the first natural flexural frequency, the bridge is considered as simply supported, for which equation (3) applies.

$$
f\left(K_{n} ; d_{T C}\right)=\frac{K_{n}}{2 \pi} \sqrt{\frac{E I_{x} \cdot g}{\gamma_{M, S L S} \cdot\left[q_{S W} \cdot B_{\text {bridge }} / \eta_{c l, t}+d_{T C} \cdot P \cdot B_{u s e} / \eta_{c s, t}\right] \cdot L_{s p a n}{ }^{4}}}
$$

With [60]:

$K_{n} \quad$ Constant depending on the boundary conditions of the footbridge, equal to 9.87 for a simply supported beam;

$g \quad$ Constant describing the gravitational acceleration, equal to $9.8116 \mathrm{~m} / \mathrm{s}^{2}$;

$\gamma_{M, S L S}$ Material factor for an FRP laminate taking into account the geometric deviations and model uncertainties and the uncertainties in the strength properties of the material. In the SLS, the partial material factor is equal to 1.00;

$q_{S W} \quad$ Self-weight of the structural parts, non-structural surfacing and of auxiliary elements such as handrails $\left[\mathrm{kN} / \mathrm{m}^{2}\right]$;

$d_{T C} \quad$ Pedestrian density as defined by the traffic classes in the JRC document 'Design of Lightweight Footbridges for Human Induced Vibrations';

$P \quad$ Mass of one person, equal to $70 \mathrm{~kg}$;

$\eta_{c l, t} \quad$ Conversion factor taking into account the effects of environmental factors and aging for the vibrational assessment under quasi permanent loading, equal to 0.810;

$\eta_{c s, t} \quad$ Conversion factor taking into account the effects of environmental factors and aging for the vibrational assessment under short-term load, equal to 0.810 .

Using the formula above, Figure 19 shows the value of the first natural flexural frequency for the GFRP web-core footbridge in Puurs as a function of the pedestrian density. The first natural flexural frequency in unloaded state of the bridge can be read at a pedestrian density of $0 \mathrm{P} / \mathrm{m}^{2}$. Comparison to the values obtained from the heel and excitation tests (i.e. $3.81 \mathrm{~Hz}$ and $3.79 \mathrm{~Hz}$ 
respectively) as well as to the value obtained from the comfort analysis test under a pedestrian density of $0.5 \mathrm{P} / \mathrm{m}^{2}$ requires assigning a value of one to the conversion factors $\left(\eta_{c l, t}\right.$ and $\left.\eta_{c s, t}\right)$, corresponding to the initial stiffness values without time-dependent deterioration. For reference, the calculated values at the end of the design life (100 years) are also added to the graph. Due to the stiffness degradation, an on average $11 \%$ decrease in first natural flexural frequency is noted.

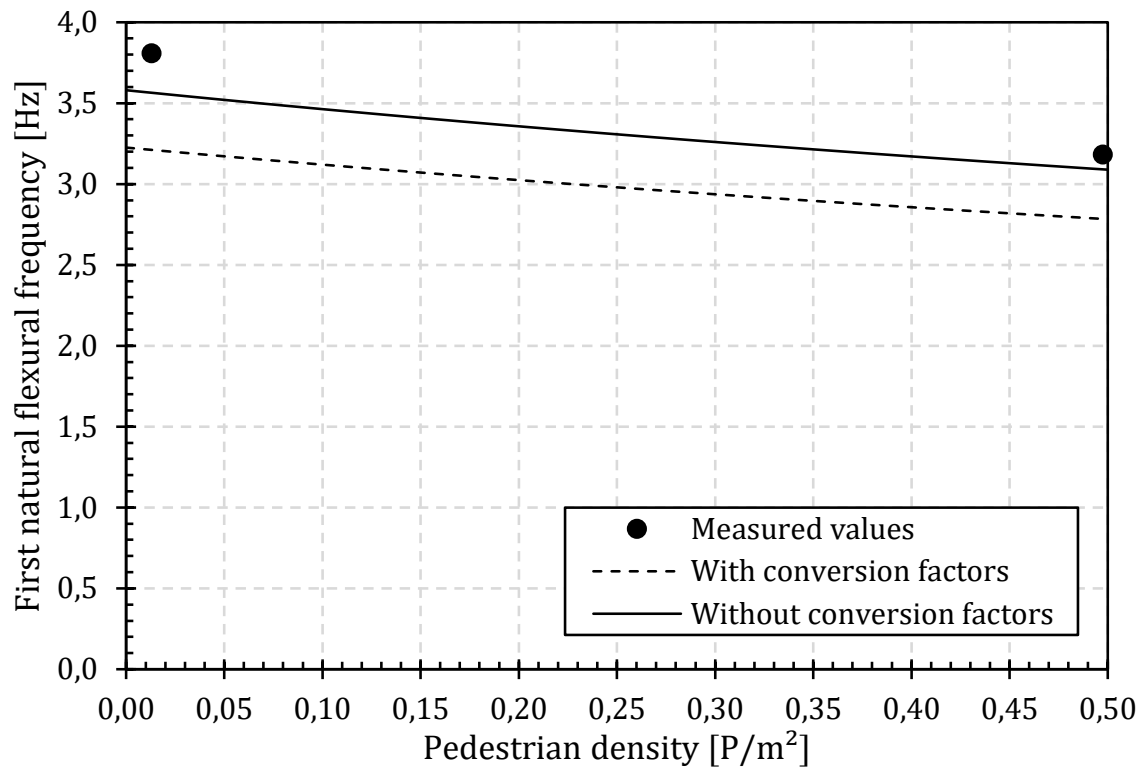

Figure 19: Evolution of the first natural flexural frequency with and without conversion factors as a function of the pedestrian density on the GFRP web-core footbridge in Puurs as calculated by CUR96:2019

A value of $3.58 \mathrm{~Hz}$ is found for the first natural flexural frequency in unloaded condition (with conversion factors equal to 1 ), this is only $5.89 \%$ lower than the average measured value of 3.80 $\mathrm{Hz}$ from the heel and excitation test with one person. For a pedestrian density of $0.5 \mathrm{P} / \mathrm{m}^{2}$, the first natural flexural frequency without conversion factors is equal to $3.09 \mathrm{~Hz}$, which is a difference of $2.83 \%$ with the measured value of $3.18 \mathrm{~Hz}$ of Table 3 during the comfort analysis tests with 38 people.

Note that the analytical calculation does not take into account the influence of the handrail on the natural frequency and weight of the bridge, which in reality will have a small influence depending on the shape and structure of the handrail. It can therefore be concluded that the analytical calculation gives a good representation of the actual situation, provided that the conversion factors are assigned unity values.

\subsection{Comfort analysis}

The comfort of the bridge is assessed based on the maximum vertical accelerations of the bridge caused by pedestrian traffic. The JRC document [45] will be used as a guideline. The maximum vertical acceleration of the bridge can be calculated from equation (4).

$$
a_{\text {max }, \text { vert }}=k_{a, 95 \%} \sqrt{\frac{C \cdot \sigma_{F}{ }^{2}}{M_{i}{ }^{2}} \cdot k_{1} \cdot \xi^{k_{2}}}
$$

With [45]:

$k_{a, 95 \%} \quad 95^{\text {th }}$ percentile of the peak factor for the transformation of the standard deviation of the stresses to the characteristic design value of the vertical acceleration in serviceability limit state; 
C constant describing the maximum of the load spectrum;

$\sigma_{\mathrm{F}}^{2} \quad$ variance of the loading (pedestrian induced forces);

$$
\begin{array}{ll}
\multicolumn{1}{c}{\sigma_{F}^{2}=k_{F} \cdot n} \\
k_{F} & \text { Constant }\left[\mathrm{kN}^{2}\right] \\
n=d_{T C} \cdot L_{\text {bridge }} \cdot B_{\text {use }} & \text { Number of pedestrians on the bridge }
\end{array}
$$

$\mathrm{M}_{\mathrm{i}}^{2} \quad$ squared modal mass of the considered mode $\mathrm{i}$;

$\mathrm{k}_{1}, \mathrm{k}_{2} \quad$ constants depending on the pedestrian density

$$
\begin{array}{ll}
\qquad \begin{array}{c}
k_{1}=a_{1} f_{i}^{2}+a_{2} f_{i}+a_{3} \\
k_{2}=b_{1} f_{i}^{2}+b_{2} f_{i}+b_{3}
\end{array} \\
\mathrm{a}_{1}, \mathrm{a}_{2}, \mathrm{a}_{3}, \mathrm{~b}_{1}, \mathrm{~b}_{2}, \mathrm{~b}_{3} \quad \begin{array}{l}
\text { constants } \\
\mathrm{f}_{\mathrm{i}}
\end{array} \\
\begin{array}{l}
\text { considered first natural flexural frequency that coincides with } \\
\text { the mean step frequency of the pedestrian stream; }
\end{array}
\end{array}
$$

$\xi \quad$ structural damping ratio.

The value of the structural damping ratio of the bridge depends on many factors, including the construction details, fibre orientations and fibre volume content. The damping of a structure is generally larger than the material damping due to the presence of connections with the environment and in the structure itself. The CUR96:2019 [60] gives a minimum value for the damping ratio for a GFRP material of $0.5 \%$ and an average value of $1.0 \%$. However, in practice, as seen from the results of the heel and excitation tests, the damping ratio of the bridge structure will be larger due to the existing boundary and support conditions. The use of higher damping values than mentioned in the CUR96:2019 and damping values for non-standard materials must be substantiated by representative experimental data.

The design value of the vertical acceleration of the bridge can be found by multiplying the maximum vertical acceleration with a reduction coefficient $\psi$, which takes into account the probability that the step frequency approaches the critical range of the first natural flexural frequencies of the bridge. Consequently, this reduction coefficient depends on the first natural flexural frequency for a given pedestrian traffic. The value of the reduction coefficient is shown in Figure 6.

$$
a_{d, \text { vert }}=\psi \cdot a_{\text {max,vert }}
$$

The results for the vertical acceleration for the different traffic classes and for a structural damping ratio of $0.5 \%, 1.0 \%, 1.94 \%$ and $2.72 \%$ are depicted in Figure 20. The damping ratios $0.5 \%$ and $1.0 \%$ are the minimum and average values specified by the CUR96:2019, while the damping ratios $1.94 \%$ and $2.72 \%$ are the minimum and maximum values respectively, obtained from the heel and excitation tests on the GFRP web-core footbridge in Puurs. In addition to the calculated values, the figure also displays the maximum (MAX) and root mean square (RMS) value of the measured vertical accelerations for 8,15 and 38 walking people on the bridge deck. 


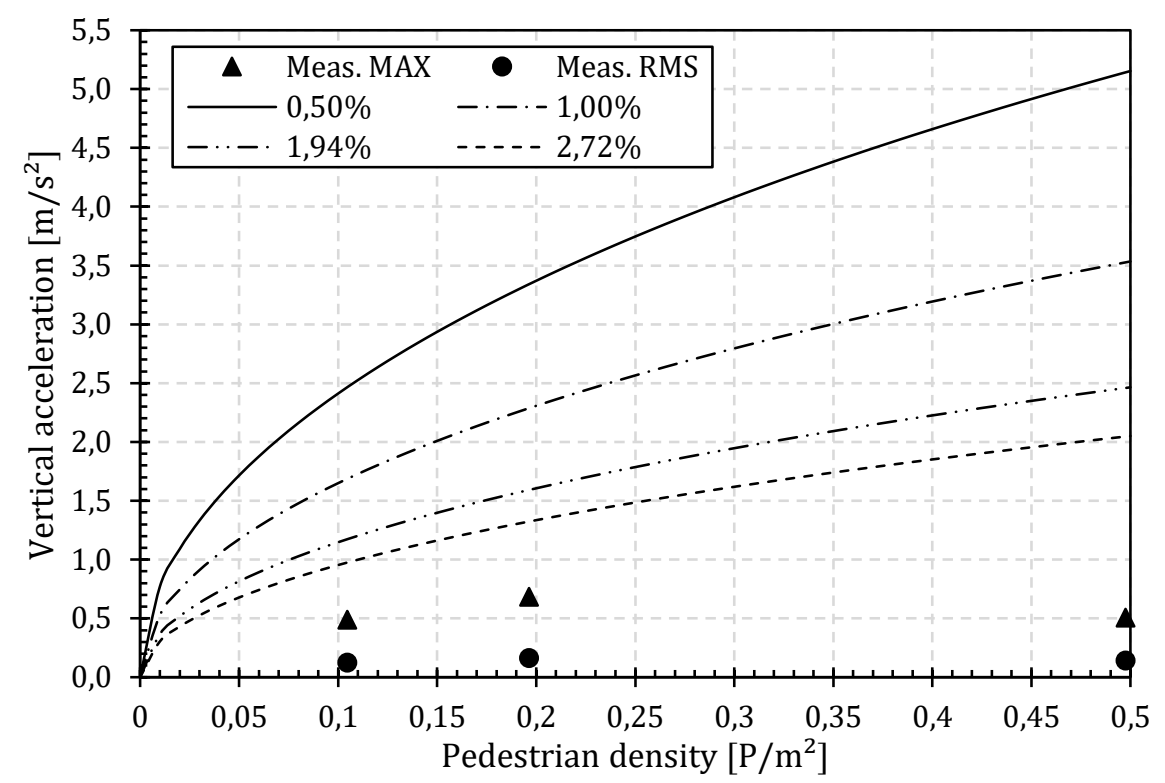

Figure 20: Confrontation of measured vertical acceleration as a function of the pedestrian density to predictions for different structural damping ratios for the GFRP web-core footbridge in Puurs

From Figure 20, it can be concluded that a maximum comfort, linked to comfort class CC1 and a design vertical acceleration less than $0.5 \mathrm{~m} / \mathrm{s}^{2}$, can only be achieved in the analytical calculation for very small pedestrian densities, i.e. smaller than $0.01 \mathrm{P} / \mathrm{m}^{2}$ for a damping ratio of $0.5 \%$ and smaller than $0.03 \mathrm{P} / \mathrm{m}^{2}$ for a damping ratio of $2.72 \%$. The discomfort linked to comfort class CC4 and a vertical acceleration greater than $2.5 \mathrm{~m} / \mathrm{s}^{2}$ on the other hand occurs in the analytical calculation with a damping ratio of $0.5 \%, 1.0 \%$ and $1.94 \%$ at a pedestrian density greater than $0.11,0.24$ and $0.5 \mathrm{P} / \mathrm{m}^{2}$ respectively. Only for the maximum damping ratio of $2.72 \%$, no such discomfort for the pedestrians on the bridge will occur in the analytical calculation model. However, the measured MAX and RMS values for the 'walking' load case show that no such discomfort takes place, with vertical accelerations that comply with CC2 for all pedestrian densities. If only the RMS value of the vertical acceleration is considered, the GFRP web-core footbridge of Puurs can be classified under CC1, with vertical accelerations smaller than $0.5 \mathrm{~m} / \mathrm{s}^{2}$.

A confrontation with the measured values of maximum accelerations (See Table 6 and Figure 20) proves that the analytically calculated values do not provide a reasonable estimation of the actual comfort levels of the Puurs bridge, even when a test-based value of the damping ratio is available. This can be attributed to human-induced damping [7,29,70-72]. Moreover, the effect of this additional damping becomes more pronounced for higher pedestrian densities, since the ratio of the predicted to the measured acceleration becomes ever larger.

This observation is in line with the conclusions from section 4, and is an important step in the understanding of the vibrational comfort analysis of GFRP web-core sandwich bridges, which are prone to vibrations but benefit, probably more than any other bridge type, from human-induced damping.

\section{Conclusions}

This paper reports experimental data for the dynamic properties (i.e. first fundamental flexural frequency, damping ratio, comfort class) of ten web-core sandwich panel FRP composite footbridges in the Flanders region of Belgium, which contributes to the assessment of relevant input parameters for design and assessment of this promising bridge type, quickly gaining popularity in recent years. The main conclusions are: 
- Data gathering based on smartphone accelerometers is a quick, affordable, and reliable method for vibrational analysis of GFRP web-core bridges.

- Both the heel and excitation test methods are reliable methods for data gathering, although for very stiff bridges, only the heel test may be successful.

- The tests indicate minimum, maximum and average damping ratios of $1.28 \%, 4.66 \%$ and $2.12 \%$ respectively for GFRP web-core sandwich bridges, exceeding coded values.

- Comfort analysis tests with up to 0.5 people per square meter provide data for comfort analysis.

- A confrontation of measured accelerations to comfort level predictions indicate that current design guidelines for pedestrian comfort analysis are overconservative and do not reflect the effect of human-induced damping, which is especially apparent for this bridge type given its very low modal mass and relatively low damping ratio.

The results contribute to understanding the mechanical behaviour of this promising bridge type, and to the lack of fully understanding the vibrational behaviour currently adopted in calculation models, possibly leading to overconservative designs.

\section{Acknowledgment}

This research was financially supported by the TETRA Project C-Bridge (Composite Bridges Roadmap into Design, Guidelines and Execution), funded by the Flemish Agency for Innovation and Entrepreneurship (VLAIO).

\section{Data availability}

The raw/processed data required to reproduce these findings cannot be shared at this time as the data also forms part of an ongoing study.

\section{Reference}

[1] Živanović S, Wei X, Russell J, Mottram JT. Vibration Performance of Two FRP Footbridge Structures in the United Kingdom 2017. https://doi.org/10.24904/footbridge2017.09384.

[2] Živanović S, Pavic A, Reynolds P. Vibration serviceability of footbridges under human-induced excitation: A literature review. vol. 279. 2005. https://doi.org/10.1016/j.jsv.2004.01.019.

[3] Živanović S. Benchmark footbridge for vibration serviceability assessment under the vertical component of pedestrian load. J Struct Eng (United States) 2012;138:1193-202. https://doi.org/10.1061/(ASCE)ST.1943541X.0000571.

[4] Ahmadi E, Caprani C, Živanović S, Evans N, Heidarpour A. A framework for quantification of human-structure interaction in vertical direction. J Sound Vib 2018;432:351-72. https://doi.org/10.1016/j.jsv.2018.06.054.

[5] Bassoli E, Nimmen K Van, Vincenzi L, Broeck P Van Den. A spectral load model for pedestrian excitation including vertical human- structure interaction. Eng Struct 2018;156:537-47. https://doi.org/10.1016/j.engstruct.2017.11.050.

[6] Brownjohn JMW. Energy dissipation from vibrating floor slabs due to human-structure interaction. Shock Vib 2001;8:315-23. https://doi.org/10.1155/2001/454139.

[7] Heinemann P, Kasperski M. Damping Induced by Walking and Running. Procedia Eng 2017;199:2826-31. https://doi.org/10.1016/j.proeng.2017.09.537.

[8] Dallard P, Fitzpatrick AJ, Flint A, Le Bourva S, Low A, Ridsdill Smith RM, et al. The London Millennium Footbridge. Struct Eng 2001;79:17-33.

[9] Dallard P, Fitzpatrick T, Flint A, Low A, Ridsdill Smith R, Willford M, et al. London Millennium Bridge: Pedestrian Induced Lateral Vibration. J Bridg Eng 2001;6:412-7. https://doi.org/10.1061/(ASCE)1084-0702(2001)6.

[10] Tuakta C, Of M, In E. Use of Fiber Reinforced Polymer Composite in Bridge Structures By Submitted To the Department of Civil and Environmental Engineering in Fullfillment of the Requirement for the Degree of Master 
of Engineering in Civil and Environmental Engineering At the M 2005.

[11] Zyjewski A, Chróścielewski J, Pyrzowski Ł. The use of fibre-reinforced polymers (FRP) in bridges as a favourable solution for the environment. E3S Web Conf 2017;17. https://doi.org/10.1051/e3sconf/20171700102.

[12] Wan B. Using fiber-reinforced polymer (FRP) composites in bridge construction and monitoring their performance: An overview. Adv. Compos. Bridg. Constr. Repair, Elsevier Inc.; 2014, p. 3-29. https://doi.org/10.1533/9780857097019.1.3.

[13] Van Den Einde L, Zhao L, Seible F. Use of FRP composites in civil structural applications. Constr. Build. Mater., 2003. https://doi.org/10.1016/S0950-0618(03)00040-0.

[14] Karbhari VM. Material Considerations in FRP Rhabilitation of concrete structures. J Mater Civ Eng 2001;13:907.

[15] Sonnenschein R, Gajdosova K, Holly I. FRP Composites and their Using in the Construction of Bridges. Procedia Eng., 2016. https://doi.org/10.1016/j.proeng.2016.08.665.

[16] Mara V, Haghani R, Harryson P. Bridge decks of fibre reinforced polymer (FRP): A sustainable solution. Constr Build Mater 2014. https://doi.org/10.1016/j.conbuildmat.2013.09.036.

[17] Piras S, Chin K. Footbridge design for pedestrian induced vibrations. Concr NZ 2018;3.

[18] Chróścielewski J, Miśkiewicz M, Pyrzowski Ł, Sobczyk B, Wilde K. A novel sandwich footbridge - Practical application of laminated composites in bridge design and in situ measurements of static response. Compos Part B Eng 2017;126:153-61. https://doi.org/10.1016/j.compositesb.2017.06.009.

[19] De Corte W, Jansseune A, Van Paepegem W, Peeters J. Structural behaviour and robustness assessment of an InfraCore ${ }^{\circledR}$ inside bridge deck specimen subjected to static and dynamic local loading. ICCM Int Conf Compos Mater 2017;2017-Augus:20-5.

[20] Stankiewicz B. Composite GFRP deck for bridge structures. Procedia Eng 2012;40:423-7. https://doi.org/10.1016/j.proeng.2012.07.119.

[21] Tuwair H, Drury J, Volz J. Testing and evaluation of full scale fiber-reinforced polymer bridge deck panels incorporating a polyurethane foam core. Eng Struct 2019;184:205-16. https://doi.org/10.1016/j.engstruct.2019.01.104.

[22] Vovesný M, Rotter T. GFRP bridge deck panel. Procedia Eng 2012;40:492-7. https://doi.org/10.1016/j.proeng.2012.07.131.

[23] De Corte W, Uyttersprot J, Somers R. FRP bridges in the Flanders region : Experiences from the C-bridge project 2020.

[24] Kim YJ. State of the practice of FRP composites in highway bridges. Eng Struct 2019. https://doi.org/10.1016/j.engstruct.2018.10.067.

[25] Russell JM, Wei X, Živanović S, Kruger C. Vibration serviceability of a GFRP railway crossing due to pedestrians and train excitation. Eng Struct 2020;219:0-13. https://doi.org/10.1016/j.engstruct.2020.110756.

[26] De Corte W, Jansseune A, Van Paepegem W, Peeters J. Elastic properties and failure behavior of tiled laminate composites. Key Eng Mater 2018;774 KEM:564-9. https://doi.org/10.4028/www.scientific.net/KEM.774.564.

[27] Bai Y, Keller T. Modal parameter identification for a GFRP pedestrian bridge. Compos Struct 2008;82:90-100. https://doi.org/10.1016/j.compstruct.2006.12.008.

[28] Ahmadi E, Caprani C, Živanović S, Heidarpour A. Assessment of human-structure interaction on a lively lightweight GFRP footbridge. Eng Struct 2019;199. https://doi.org/10.1016/j.engstruct.2019.109687.

[29] Van Nimmen K, Lombaert G, de Roeck G, Van Den Broeck P. Human-induced vibrations of footbridges: The effect of vertical human-structure interaction. Conf. Proc. Soc. Exp. Mech. Ser., vol. 4, Springer New York LLC; 2016, p. 299-307. https://doi.org/10.1007/978-3-319-29763-7_29.

[30] Ellis BR, Ji T. Human-structure interaction in vertical vibrations. Proc Inst Civ Eng Struct Build 1997;122:1-9. https://doi.org/10.1680/istbu.1997.29162.

[31] Friehe M, Heinemeyer C, Feldmann M. Design of highly sensitive floors for human induced vibrations. Procedia Eng 2017;199:2796-801. https://doi.org/10.1016/j.proeng.2017.09.549.

[32] Mohammed AS, Pavic A. Effect of Walking people on Dynamic Properties of Floors. Procedia Eng 2017;199:2856-63. https://doi.org/10.1016/j.proeng.2017.09.561.

[33] Tamura Y, Suganuma SY. Evaluation of amplitude-dependent damping and natural frequency of buildings during strong winds. J Wind Eng Ind Aerodyn 1996;59:115-30. https://doi.org/10.1016/01676105(96)00003-7. 
[34] Sachse R, Pavic A, Reynolds P. Parametric study of modal properties of damped two-degree-of-freedom crowdstructure dynamic systems. J Sound Vib 2004;274:461-80. https://doi.org/10.1016/j.jsv.2003.08.052.

[35] Wei X, Živanović S, Russell J, Mottershead JE. Subsystem identification in structures with a human occupant based on composite frequency response functions. Mech Syst Signal Process 2019;120:290-307. https://doi.org/10.1016/j.ymssp.2018.09.018.

[36] Pimentel RL. Vibrational performance of pedestrian bridges due to human-induced loads, PhD Thesis, University of Sheffield, Sheffield, UK 1997.

[37] Hivoss. Design of Footbridges : Guideline. Res Fund Coal Steel 2007:1-33.

[38] Van Nimmen K, Lombaert G, De Roeck G, Van den Broeck P. Vibration serviceability of footbridges: Evaluation of the current codes of practice. Eng Struct 2014;59:448-61. https://doi.org/10.1016/j.engstruct.2013.11.006.

[39] SETRA S d'Etudes $\mathrm{T}$ des $\mathrm{R}$ et A. Footbridges - Assessment of vibrational behaviour of footbridges under pedestrian loading 2006:127.

[40] Dey P, Narasimhan S, Walbridge S. Calibrating Pedestrian-Bridge Standards for Vibration Serviceability. J Bridg Eng 2018;23:1-17. https://doi.org/10.1061/(ASCE)BE.1943-5592.0001270.

[41] Wei X, Russell J, Živanović S, Toby Mottram J. Measured dynamic properties for FRP footbridges and their critical comparison against structures made of conventional construction materials. Compos Struct 2019. https://doi.org/10.1016/j.compstruct.2019.110956.

[42] Ligthart R. Forecast of the dynamic behaviour of FRP n.d.

[43] Ghent University. C-Bridge: Roadmap into design, guidelines and execution of composite bridges in Flanders 2018. https://www.ugent.be/ea/structural-engineering/en/research/schoonmeersen/projects/cbridge.htm (accessed February 6, 2020).

[44] Now Instruments + software. VibSensor User Guide n.d. http://www.now-instruments.com/get-help/5vibsensor-user-guide (accessed February 6, 2020).

[45] JRC Scientific and Technical. Design of Lightweight Footbridges for Human Induced Vibrations. 2009. https://doi.org/10.1088/1751-8113/44/8/085201.

[46] Hsiao K-T, Heider D. Vacuum assisted resin transfer molding (VARTM) in polymer matrix composites. Woodhead Publishing Limited; 2012. https://doi.org/10.1533/9780857096258.3.310.

[47] Somers R. Verslag Trillingsproef stroomafwaarts CANADA BRIDGES , BRUGES PART I : Downstream bridge Operational modal analysis Human-induced vibrations Report BWM-2019-03 n.d.

[48] Feng M, Fukuda Y, Mizuta M, Ozer E. Citizen sensors for SHM: Use of accelerometer data from smartphones. Sensors (Switzerland) 2015;15:2980-98. https://doi.org/10.3390/s150202980.

[49] Zhao X, Yu Y, Li M, Ou J. Cloud-structural health monitoring based on smartphone. Vibroengineering Procedia 2015;5:241-6.

[50] Yu Y, Han R, Zhao X, Mao X, Hu W, Jiao D, et al. Initial validation of mobile-structural health monitoring method using smartphones. Int J Distrib Sens Networks 2015;2015. https://doi.org/10.1155/2015/274391.

[51] Gonzalez R, Huerta M, Sagbay G, Clotet R, Rivas D, Pérez A, et al. Structural Health Monitoring using WifiPhones. 2015 IEEE Colomb Conf Commun Comput COLCOM 2015 - Conf Proc 2015. https://doi.org/10.1109/ColComCon.2015.7152104.

[52] Castellanos-Toro S, Marmolejo M, Marulanda J, Cruz A, Thomson P. Frequencies and damping ratios of bridges through Operational Modal Analysis using smartphones. Constr Build Mater 2018. https://doi.org/10.1016/j.conbuildmat.2018.08.089.

[53] Cahill P, Quirk L, Dewan P, Pakrashi V. Comparison of smartphone accelerometer applications for structural vibration monitoring. Adv Comput Des 2019;4:1-13. https://doi.org/10.12989/acd.2019.4.1.001.

[54] Piezotronics PCB. Model 393B04 Seismic Icp ® Accelerometer: Technical data sheet 2017:14043.

[55] Piezotronics PCB. Model 393B04 Seismic , miniature ( 50 gm ), ceramic flexural ICP $®$ accelerometr, $1 \mathrm{~V} / \mathrm{g}, 0.06$ to 450: Installation and Operating Manual n.d.

[56] Wei X, Živanović S. Frequency response function-based explicit framework for dynamic identification in human-structure systems. J Sound Vib 2018;422:453-70. https://doi.org/10.1016/j.jsv.2018.02.015.

[57] Wei X, Russell J, Živanović S, Toby Mottram J. Measured dynamic properties for FRP footbridges and their critical comparison against structures made of conventional construction materials. Compos Struct 2019;223. https://doi.org/10.1016/j.compstruct.2019.110956.

[58] Živanović S, Díaz IM, Pavić A. Influence of walking and standing crowds on structural dynamic properties. Conf 
Proc Soc Exp Mech Ser 2009.

[59] Standardization, European Committee For. 2011. 1 EN 1990:2002 - Basis of Structural Design.Standardization ECF. EN 1990:2002 - Basis of structural design. vol. 1. 2011.

[60] CROW-CUR. Aanbevelingen 96:2019 Vezelversterkte kunststoffen in bouwkundige en civieltechnische draagconstructiesfile 2019:194. https://doi.org/9789066286726.

[61] Etter DM, Gough TA, Cheng YF. Direct computation of second-oredr coefficients for bandpass and bandstop digital filters. Signal Processing 1990;19:27-41.

[62] Ellis G. Filters in Control Systems. Control Syst Des Guid 2012:165-83. https://doi.org/10.1016/b978-0-12385920-4.00009-6.

[63] Chaparro LF. Introduction to the Design of Discrete Filters. 2011. https://doi.org/10.1016/b978-0-12-3747167.00015-6.

[64] Ansari R. Digital Filters. Passiv Act Digit Filters 2009:III-1-III-2. https://doi.org/10.1016/B978-0-12-3708670.50013-9.

[65] Härdle W. Smoothing techniques. Appl Nonparametric Regres 2008:24-86. https://doi.org/10.1017/ccol0521382483.003.

[66] Warner RA. Moving Averages for Identifying Trends and Changes in the Data. Optim Disp Interpret Data 2016:53-73. https://doi.org/10.1016/b978-0-12-804513-8.00003-1.

[67] Smith SW. Moving Average Filters. Digit Signal Process 2003:277-84. https://doi.org/10.1016/b978-0-75067444-7/50052-2.

[68] Wei X, Russell J, Živanović S, Mottram JT. Measured dynamic properties for FRP footbridges and their critical comparison against structures made of conventional construction materials. Compos Struct 2019;223:110956. https://doi.org/10.1016/j.compstruct.2019.110956.

[69] Van Nimmen K, Lombaert G, De Roeck G, Van den Broeck P. The impact of vertical human-structure interaction on the response of footbridges to pedestrian excitation. J Sound Vib 2017;402:104-21. https://doi.org/10.1016/j.jsv.2017.05.017.

[70] Kasperski M. Damping induced by pedestrians. Proc Int Conf Struct Dyn , EURODYN 2014;2014-Janua:105964.

[71] Nimmen K Van, Maes K, Živanovi S, Lombaert G, Roeck G De, Broeck P Van Den. Identification and Modelling of Vertical Human-Structure Interaction 2015;2:319-30. https://doi.org/10.1007/978-3-319-15248-6.

[72] Nimmen K Van, Lombaert G, Roeck G De, Broeck P Van Den. The impact of vertical human-structure interaction on the response of footbridges to pedestrian excitation. J Sound Vib 2017;402:104-21. https://doi.org/10.1016/j.jsv.2017.05.017.

\section{Figure captions}

Figure 1: Studied bridges in the Flanders region of Belgium

Figure 2: Main axes of the accelerometer in the device [44]

Figure 3: Top view of the measuring grid and naming of the measuring points for the heel and excitation test

Figure 4: Mean first natural flexural frequency from the heel and excitation test for the considered GFRP web-core footbridges

Figure 5: First natural flexural frequency as a function of the relative bridge length for a pedestrian load of $0.5 \mathrm{P} / \mathrm{m}^{2}$ (TC3)

Figure 6: Reduction coefficient for pedestrian traffic as a function of the first natural flexural frequency [60]

Figure 7: Raw vibrations in the three main directions at MP3 for a heel test in Maldegem

Figure 8: Logarithmic decrement of the third vibration during the heel test in Maldegem

Figure 9: Damping ratio originating from heel tests for the studied GFRP bridges for different lengths and one person

Figure 10: Damping ratio originating from heel tests for the studied GFRP bridges for different lengths and two people

Figure 11: Percentage increase of the damping ratio under a load of 1 person with respect to that under a load of two people

Figure 12: Raw vibrations in the three main directions at MP3 for an excitation test in Ghent 
Figure 13: Logarithmic decrement of the vibration during the excitation test in Ghent

Figure 14: Damping ratio originating from the excitation test for the studied GFRP bridges for one and two people

Figure 15: Percentage increase in damping ratio between a GFRP footbridge loaded with one person and two people

Figure 16: Evolution of the damping ratio as a function of the percentage pedestrians on the bridge deck

Figure 17: Top view of the measuring grid and designation of the measuring points for the human-induced vibration tests

Figure 18: Vertical acceleration while walking (left) and jogging (right) for TC1, TC2 and TC3 on the GFRP footbridge in Tremelo

Figure 19: Evolution of the first natural flexural frequency with and without conversion factors as a function of the pedestrian density on the GFRP web-core footbridge in Puurs as calculated by CUR96:2019

Figure 20: Confrontation of measured vertical acceleration as a function of the pedestrian density to predictions for different structural damping ratios for the GFRP web-core footbridge in Puurs

\section{Table captions}

Table 1: Overview of the tested GFRP web-core footbridges in the Flanders region [23]

Table 2: Mean first natural flexural frequency and coefficient of variation for the heel and excitation test for the considered GFRP web-core footbridges

Table 3: General information of the first natural flexural frequency of the comfort analysis test with a pedestrian density of $0.5 \mathrm{P} / \mathrm{m}^{2}$

Table 4: Pedestrian densities used during the tests as defined in the JRC document

Table 5: Number of people for the human-induced vibration test for different pedestrian densities

Table 6: Maximum and RMS value for the $\mathrm{Z}$ accelerations during walking for various pedestrian densities

Table 7: Maximum and RMS value for the $\mathrm{Z}$ accelerations during jogging for different pedestrian densities

Table 8: Geometrical properties of the Puurs bridge 